\title{
About detectability and limits of detection in single particle inductively coupled plasma mass spectrometry
}

\author{
Francisco Laborda *, Ana C. Gimenez-Ingalaturre, Eduardo Bolea, Juan R. Castillo \\ Group of Analytical Spectroscopy and Sensors (GEAS) \\ Institute of Environmental Sciences (IUCA) \\ University of Zaragoza \\ Pedro Cerbuna 12, 50009 Zaragoza, Spain. \\ * corresponding author. E-mail: flaborda@unizar.es
}

\begin{abstract}
Single particle inductively coupled plasma mass spectrometry (SP-ICP-MS) offers unique features for the detection of particles, as well as for their quantification and size characterization. The detection capabilities of SP-ICP-MS are therefore not only limited to the concentration domains (of particles and dissolved related species), but also to the mass of element per particle and particle size domains. Discrimination and detection of particle events, based on the use of robust limits of decision (also known as critical values), and the estimation of the limits of detection in the different domains, require standardized metrological approaches that have not been clearly established yet. As a consequence, harmonized approaches and expressions to allow reliable comparisons between methods and instruments, as well as to process SP-ICP-MS data, are required. This paper is an attempt to summarize and review the different approaches applied up to now in relation to the detectability in SP-ICP-MS, and highlight the peculiarities of this topic in SP-ICP-MS. A holistic approach with criteria and expressions for the estimation of the different critical values and limits of detection in terms of the different instrumental and experimental parameters involved is proposed. Additionally, a calculation tool for estimating and predicting critical values and limits of detection under different experimental conditions is also included.
\end{abstract}

Key words: single particle detection; ICP-MS; limit of detection; critical value; nanoparticle 


\section{Introduction}

The use of inductively coupled plasma mass spectrometry (ICP-MS) for the analysis of particles on a particle-by-particle basis has led to the development of a technique commonly referred as single particle ICP-MS (SP-ICP-MS). Although its origins can be traced back to the previous century [1,2], a seminal paper · by Degueldre and Favarger in 2003 [3] outlined the principles behind SP-ICP-MS and showed the feasibility of using ICP-MS for the analysis of colloids. However, the driving force that explain the rapid evolution of the techique from 2011 has been its application to the analysis of nanoparticles [4,5], along with the new developments in commercial ICP-MS instruments and software in recent years [6-8]. The success of SP-ICPMS lies in its unique features for the detection, characterization and quantification of particles in liquid suspensions, which have been discussed in a number of reviews $[1,2,9,10]$.

SP-ICP-MS, like any other analytical methodology, has limited detection capabilities. Because of the different types of information that it can provide [9], these capabilities are related to concentrations, but also to mass of element per particle (and particle size when additional informations about shape, composition and density of the particles are available). Moreover, concentration information not only involves particle number, but also mass concentration of dissolved species. As a consequence, all these detection capabilities of SP-ICPMS should be expressed quantitatively as the corresponding limits of detection (LOD).

Although the usefulness of LODs have been questioned by some authors [11,12], they are considered a fundamental metrological parameter and they have been defined by IUPAC [13] and ISO [14] for quantitative methods. LODs are used both for characterizing and validating analytical methods. Additionally, instrumental LODs are commonly used as figures of merit designed to quantify the detection capability of the purely instrumental aspect of an analytical method [15]. In spite of its broad use, LODs remain a complex topic and some confusion exists around them, which is the result of the different approaches available for their estimation [16]. This is also the case in SP-ICP-MS, although aggravated by the following facts: (i) SP-ICP-MS is a counting technique, governed by Poisson statistics, with respect to the signals (counted ions) and the particles as well; (ii) blanks and baseline levels can be very close to zero; (iii) in a typical measurement process, the occurrence of baseline events is larger than that of particles (at least one order of magnitude); and (iv) both concentration and size (or mass of element per particle) LODs must be considered. In spite of the complexity of the problem, and for the shake of simplicity, the estimation of the different types of LODs in most of the SP-ICP-MS publications are based on the conventional IUPAC approaches for concentration LODs, although with different interpretations depending on the authors, causing certain level of confusion. This has been also the case with the discrimination and detection of particles in relation with the processing of SP-ICP-MS raw data or the screening of samples for the assessment of the presence/absence of particles, where limits of decision (also known as critical 
values) must be used. In this regard, just a limited number of publications have partially addressed these issues, adapting the conventional LOD approaches to the peculiarities of SPICP-MS [17-20].

The aims of this article are to review critically the different approaches applied in relation to the detectability issues in SP-ICP-MS and to present a holistic approach to the topic, considering all the special features of this technique. It should be considered as an attempt to open an harmonization process about detectability and limits of detection in SP-ICP-MS. An updated summary of limits of detection achievable with commercial quadrupole ICP-MS instruments has been included as well as a calculation tool for their determination and prediction under different experimental conditions.

\section{Overview of the concentration LOD concept}

The concept and approaches for estimation of concentration LODs have been discussed in a number of comprehensive reviews [21,22] and the references therein. In a broad sense, a concentration LOD is defined as the lowest concentration of an analyte that can be detected with a stated reasonable uncertainty. Intuitively, this concentration corresponds to the lowest signal obtained from a sample containing analyte that is significantly different from the blank signal, which has been obtained from a sample containing no analyte. The most widely used approach for estimation of concentration LODs was developed by Currie [23], both for normal and Poisson distributed data, and it is based on the hypothesis testing theory and the occurrence and control of false positives and false negatives.

The limit of detection is the value at which a given analytical method may be relied upon to lead to detection, and is defined a priori, being used to select or compare methods. Once the method is being used, the limit of detection should not play any role in the detection decision, since this is taken once the result of the measurement is known, that is, a posteriori. In fact, it is the critical value, also known as the limit of decision, the parameter to be use for deciding $a$ posteriori whether or not the result of an analysis indicates detection [23].

The concepts and expression related to critical values and LODs to be considered along this review are summarized in the supplementary material.

\section{ICP-MS and SP-ICP-MS signals}

Although the theoretical basis of single particle detection applied to ICP-MS was outlined by Degueldre et al. [3] for nanoparticle suspensions continuously introduced through conventional nebulization systems, a unified approach to support the expressions used in the different domains covered by SP-ICP-MS is presented in this section. 
The relationship between the signal $Y_{R}$ (ions counted per time unit) and the mass concentration of an element $\mathrm{M}\left(X^{M}\right)$, which is nebulized into an ICP-MS can be expressed as $[1,17]$ :

$$
Y_{R}=K_{R} X^{M}=K_{\text {intro }} K_{I C P M S} K_{M} X^{M}
$$

where $K_{R}$ is the analytical sensitivity obtained from a conventional calibration (signal intensity in cps vs. element mass concentration); $K_{\text {intro }}\left(=\eta Q_{\text {sam }}\right)$ is a factor related to the sample introduction, with $\eta$ the analyte transport efficiency and $Q_{\text {sam }}$ the sample introduction flow rate, $K_{I C P M S}$ is the detection efficiency, which represents the ratio of the number of ions detected versus the number of analyte atoms of the measured isotope introduced into the ICP; and $K_{M}$ ( $\left.=A N_{A v} / M_{M}\right)$ is a factor related to the element measured, where $A$ is the atomic abundance of the isotope considered, $N_{A v}$ the Avogadro number, and $M_{M}$ the atomic mass of the element.

SP-ICP-MS signals are recorded as time scans (Fig. 1a), which consist of a number of particle events above a continuous baseline. Whereas the intensity of each event is due to the ions detected from each particle, the baseline is due to the background at the mass recorded or to the presence of dissolved forms of the element measured. Raw time scans can be processed by plotting the event intensity vs. the event intensity frequency, obtaining histograms as shown in Fig. 1b, where the first distribution is due to the background and/or the presence of dissolved forms of the element measured and the second to the particles themselves.

The basic assumption behind the measurements in SP-ICP-MS is that each recorded event represents a single particle. If this assumption is true, then the number of particle events counted $\left(Y_{N}\right)$ during an acquisition time $\left(t_{i}\right)$ is directly related to the number concentration of particles ( $\left.X^{N}\right)$ :

$$
Y_{N}=K_{N} X^{N}=K_{\text {intro }} t_{i} X^{N}
$$

where $K_{N}$ is the analytical sensitivity obtained from a number concentration calibration (number of particle events counted vs. number concentration) during a specific acquisition time $t_{i}$. It is assumed that the transport efficiency for dissolved species and particles is the same $\left(K_{N}=\right.$ $K_{\text {intro }} t_{i}$ ), otherwise the particle transport efficiency should be considered. Both in equations 1 and 2, blanks have been considered negligible. On the other hand, the net intensity of each particle event $\left(S_{P}=Y-Y_{B}\right.$, where $Y$ is the gross intensity and $Y_{B}$ is the mean intensity of the baseline distribution, both measured as counts) is proportional to the number of atoms of the element monitored in each detected particle, and hence to the mass of element per particle $\left(m_{P}\right)$ :

$$
S_{P}=K_{m} m_{P}=K_{I C P M S} K_{M} m_{P}
$$


where $K_{m}$ is the slope obtained from a mass per particle calibration (net event intensity vs. element mass per particle). Equation 3 can be related to the size of the particle if the composition, shape and density of the particle are known. For instance, for a solid, homogeneous and spherical particle, equation 3 can be written as:

$$
S_{P}=K_{d} d^{3}=\frac{1}{6} \pi \rho F_{P} K_{I C P M S} K_{M} d^{3}
$$

where $K_{d}$ is the slope obtained from a size calibration (net event intensity vs. particle diameter cubed), $d$ is the diameter, $\rho$ the density and $F_{P}$ the mass fraction of the element in the particle. Fig. 1c shows the corresponding mass of element per particle or size distribution.

Particle events are recorded in SP-ICP-MS as pulses or as transient signals, depending on the dwell time selected. When using dwell times in the millisecond range (3-10 ms), larger that the duration of the particle event in the instrument (usually 300-1000 $\mu$ s [24,25]), events are recorded as pulses, consisting of just one reading, whereas for dwell times in the microsecond range (10-200 $\mu \mathrm{s})$, they are recorded as transient signals, comprising several readings (figure 2). This distinction comes from the technical features of SP-ICP-MS instrumentation, with former instruments limited to millisecond dwell times, applying an analyzer settling time between readings in most instruments, whereas dwell times have been reduced down to $10 \mu \mathrm{s}$, with no settling time, in current commercially available instruments. In any case, the total net intensity of a transient event can be related to the sum of the individual net intensities recorded along the transient signal $\left(S_{P}=\sum S_{P_{i}}\right)$, being equal to the net intensity of the same particle recorded as a pulse. Whereas the total net intensity of a transient event is independent of the dwell time, its height is proportional to it if the event is recorded in more than one reading, as it is shown in figure 2. Assuming a simplified triangular profile of height $S_{P_{\max }}$ and time-width $w$ for a transient particle event, and at least two readings are recorded per particle $\left(t_{d w e l l} \leq w / 2\right)$, equation 3 can be written as:

$$
S_{P_{\max }}=\frac{2}{w} K_{I C P M S} K_{M} t_{d w e l l} m_{P}
$$

The mass concentration of dissolved element $\left(X^{D}\right)$, can be calculated from the net mean baseline signal $S_{\bar{D}}=Y_{\bar{D}}-Y_{B}$, where $Y_{\bar{D}}$ is the gross mean signal corresponding to baseline events and $Y_{B}$ the mean intensity of the baseline from a blank, all intensities expressed as counts. Considering equation 1expressed in counts $(Y)$ by including the dwell time:

$$
Y=K_{R} t_{d w e l l} X^{M}=K_{\text {intro }} K_{\text {ICPMS }} K_{M} t_{d w e l l} X^{M}
$$

the mass concentration of dissolved element is related to the net mean baseline signal through:

$$
S_{\bar{D}}=K_{R} t_{d w e l l} X^{D}=K_{\text {intro }} K_{I C P M S} K_{M} t_{d w e l l} X^{D}
$$


Equations 2, 3, 4 and 7 summarize the fundamentals behind single particle ICP-MS. Quantitative determinations of particle number concentrations are based on the linear relationship between the number of events and the number concentration (equation 2); whereas, the intensity of the particle events is proportional to the mass of analyte per particle (equation 3), or to the third power of the diameter for solid, spherical, and pure particles (equation 4), allowing the determination of element mass per particle and size distributions, respectively. Finally, the signal from the baseline is directly related to the mass concentration of dissolved species of the element monitored through equation 7.

It must be point out that if the particles behave in the ICP-MS in the same way than the dissolved element, information from conventional calibration with dissolved standards $\left(K_{R}=\right.$ $K_{\text {intro }} K_{I C P M S} K_{M}$ ) can be used for the calculation of the different coefficients included in equations 1, 2 and 3, once the analyte transport efficiency and the sample flow rate are known. Analyte transport efficiency is commonly calculated following the procedures developed by Pace et al. [5].

Unlike conventional quantitative chemical measurement process, where just the signal and the concentration domains are involved, SP-ICP-MS measurement involves different domains (Figure 1). First, from the event intensity signal domain $(Y)$, particles of different sizes (in fact, of different mass of element per particle) are detected, involving a size (or an element mass per particle) domain. Transformation from the event intensity signal domain to the size or the element mass per particle domains implies the use of equations 4 and 3, respectively. Once the particle events have been detected and counted, from the number of events signal domain ( $Y_{N}$ ) we can move to the number concentration domain through the use of equation 2. Finally, the event intensity signal domain corresponding to the baseline events $\left(S_{\bar{D}}\right)$ must be considered in relation with the dissolved element mass concentrations domain through the use of equation 7.

\section{Detection capability of particles}

One of the most critical issues in SP-ICP-MS is the identification of particles events in the raw time scan. Particle events can consist of pulses, made of just one reading, or transient signals, made of a number of readings (figure 2). In both cases, the height of the particle event must be large enough to be distinguished from the baseline and its associated noise. This means that robust criteria to discriminate particle events from baseline events are required, which will also determine the minimum size or element mass per particle that can be detected. On the other hand, inappropriate criteria will lead to baseline events to be considered as particles, affecting the minimum number of particles than can be detected over a certain size, as it will be shown in the next section. 


\subsection{Discrimination of particle from baseline events}

Discrimination of particle from baseline events can be accomplished by focusing on the baseline but also on the particles. When particle events are recorded as pulses, the use of a threshold criterion related to the baseline is imperative; however, when they are recorded as transient signals, approaches similar to those applied to the detection of chromatographic peaks can be used [8] [26]. These later approaches involve the application of algorithms which consider other criteria apart from the baseline threshold, such as the peak width. In any case, the use of a threshold, which usually consists of a multiple of the baseline standard deviation (nsigma criterion), resembles the critical value $\left(Y_{C}\right)$ used in the treatment of conventional concentration detection limits (section S1 of supplementary material) and most authors have used it in such way, applying coefficients from 3 up to 8 [5,8,25,28-44].

The parallelism between the threshold criteria for discrimination of particles from baseline events and the conventional concentration detection limits theory is just apparent and its application is not straightforward. First, the intensity of the baseline readings follows Poisson distributions and consists of discrete values $(0,1,2 \ldots$ counts); second, the mean baseline intensities can cover a wide range of values, but they can be extremely low (e.g. 0.001 counts); third, the magnitude of the baseline distribution (see figure $1 \mathrm{~b}$ ), expressed as the number of baseline readings, can be very high dependant on the acquisition and the dwell times selected (e.g. more than 1 million readings).

Figure 3 shows discrete Poisson baseline distributions for mean baseline intensities from 0.001 up to 10 counts and from $10^{4}$ up to $10^{6}$ readings. Considering that for the lowest attainable baseline intensities, those distributions consisting of 0 and 1 count readings and that the critical value calculated for discrimination must be an integer (rounded up if necessary, as a rule of thumb), then the minimum critical value to be applied should be 1 count. Under these conditions, the coefficient selected is not decisive for mean baseline intensities below 1 count, obtaining the same critical values (or 1-count differences due to rounding up) by using 3 or 5 as threshold coefficients; however, from baseline mean intensities of 1 count and higher the selection becomes significant, as well as the goodness of the discrimination.

Although 3 was initially proposed as threshold coefficient [5], its use has not always been justified on statistical basis. Larger coefficients have been used with the aim of reducing the percentage of baseline readings not removed after applying the threshold criterion, which are considered false positives $[17,43]$. This means that for a normal or a Poisson-normal baseline distribution, a critical value of $3 \sigma$ implies that $0.135 \%(\alpha=0.00135)$ of the baseline readings would be false positives, following the detection limits theory. Alternantively, a threshold coefficient of 5 was proposed to reduce this percentage [43]. However, what becomes relevant in SP-ICP-MS is the absolute number of false positives, and hence the magnitude of the 
distribution, instead of its percentage. Figure 3.b shows that after applying a 3 or 5 -sigma criterion, no false positives are counted if the measurement involves $10^{4}$ readings, but 5 and 50 false positives would be detected for $10^{5}$ or $10^{6}$ readings, respectively. For higher baseline levels (figures 3.c and 3.d) around 100 false positives would be obtained when the number of readings is in the million range.

As it has been shown in figure 3, the number of baseline readings, which depends on the total acquisition time but also on the dwell time selected, becomes critical to select a threshold criterion. Working at milliseconds, the number of readings lies in the tens of thousands (e.g., 12000 readings for 1-minute acquisition time at $5 \mathrm{~ms}$ dwell time), whereas it increases to hundreds of thousands and up to more than 1 million when working at microseconds (e.g., 1.2 million readings for 1-minute acquisition time at $50 \mu \mathrm{s}$ dwell time). Under real conditions, when particles are present, the proportion of baseline readings remains high (between ca. 95 and more than $99 \%$ for milli and microsecond dwell times, respectively), because of the low number concentration of particles needed for avoiding the overlapping of two or more particles in a single event [25].

Laborda et al. [18] demostrated that a 5-sigma threshold criterion rounded to the upper integer satisfies the requirements for eliminating the occurrence of false positives along a wide range of baseline intensities working at millisecond dwell times and number of readings in the tens of thousand range. As it can be seen in figure 3, when working at microsecond dwell times and hundreds of thousands or millions of readings, the approach is also valid, although a security term $(\varepsilon \geq 1)$ could be added to the 5-sigma criterion on a practical basis to make the occurrence of false positives totally negligible. This correction applies particularly for mean baseline intensities from 1 count and one million of readings or more; under such conditions, the application of a security term equal to 1 (corrected criterion: $5 \sigma_{B}+1$ ) would limits the occurrence of false positives below 10 .

\subsection{Size and element mass per particle limit of detection}

As it has been shown above, application of a threshold strategy for discrimination of baseline and particle events is equivalent to the use of a critical value $Y_{C}$. By using a $5 \sigma$ criterion the occurrence of false positives becomes virtually zero for Poisson discrete baseline distributions. The same criterion applied for the calculation of the critical value should be used for calculation of the size (or element mass per particle) limit of detection.

The expressions found in SP-ICP-MS publications for calculation of size LODs are mainly based on the use of the $3 \sigma$ criterion $[8,17,26-32,36-42,44-46]$, although the use of a $5 \sigma$ criterion has also been reported [33-35,45]. Interpretation of a $3 \sigma$ criterion on basis of LOD theory must involve the consideration of both type I (false positives) and type II (false 
negatives) errors, where $\alpha=\beta=0.067$, but also $\alpha=0.00135$ and $\beta=0.5$, where the limit of detection is equal to the critical value $\left(Y_{D}=Y_{C}\right)$. This latter approach has been discouraged for conventional LOD calculation [47] because it involves a 50\% probability of false negatives (see figure S1b and S1d in supplementary material). However, this is not so relevant in the context of particle detection by SP-ICP-MS, because the detection of the particles is not compromised even though half of the particle distribution is lost when a LOD criterion based on $Y_{D}=Y_{C}$ is applied. This can be explained by the fact that the two distributions involved correspond to: (i) the baseline distribution, consisting of a large number of baseline readings, and (ii) the particle distribution, consisting of a much smaller number of signals produced by particles of different sizes, even for very low polydisperse particles. This approach has been followed not intentionally in most of the publications cited above, although it has proved to be effective for detection of particles in [19]. Figure 4 shows the validity of the proposed approach for detection of $97 \mathrm{~nm}$ silver nanoparticles under experimental conditions where the size LOD was $91 \mathrm{~nm}$, and half of the nanoparticle distribution could be recorded, confirming the presence of nanoparticles over $91 \mathrm{~nm}$.

Once a criterion for estimation of mass per particle and size LODs is available, it must be adapted to the nature of the particle events involved (pulses or transient signals). Working at millisecond dwell times, the total mass of element in the particle is proportional to the pulse intensity (height) through equation 3 , and the mass per particle LOD is written as:

$$
L O D_{\text {mass }}=X_{C}^{\text {mass }}=\frac{5 \sigma_{B}}{K_{I C P M S} K_{M}}
$$

For solid, homogeneous and spherical particles (equation 4), equation 8 can be expressed as:

$$
L O D_{\text {size }}=X_{C}^{\text {size }}=\left(\frac{30 \sigma_{B}}{\pi \rho F_{P} K_{I C P M S} K_{M}}\right)^{1 / 3}
$$

When using microsecond dwell times, particles events are recorded as transient signals, whose heights are proportional to the dwell time, and are always smaller than the same events recorded as pulses, as it can be seen in figure 2. By using equation 5, equations 8 and 9 can be written as:

$$
\begin{gathered}
L O D_{\text {mass }}=X_{C}^{\text {mass }}=\frac{5 \sigma_{B}}{\frac{2}{w} K_{I C P M S} K_{M} t_{d w e l l}} \\
L O D_{\text {size }}=X_{C}^{\text {size }}=\left(\frac{30 \sigma_{B}}{\frac{2}{w} \pi \rho F_{P} K_{I C P M S} K_{M} t_{\text {dwell }}}\right)^{1 / 3}
\end{gathered}
$$

Dwell time plays a significant role in relation with the achievable mass and size LODs. When using millisecond dwell times, particle events are recorded as pulses, whose intensity is independent of the dwell time; thus, mass and size LODs are limited by baseline noise and hence by the baseline intensity, which is reduced by using shorter dwell times. For a fixed 
baseline count rate $\left(Y_{R, B}\right)$ and considering that $\sigma_{B}=\sqrt{Y_{R, B} t_{d w e l l}}$, mass and size LODs decrease with the square root of the dwell time (equations 8 and 9). However, for microsecond dwell times, mass and size LODs also depend on the maximum intensity of the transient signals, which in turns depends on the dwell time used and the width of the signals. For a fixed signal width, this means that mass and size LODs increase with the square root of the dwell time when microsecond dwell times are used (equations 10 and 11). In figure 5, experimental size LODs to the third power were plotted versus the square root and the inverse of the square root of the dwell time for millisecond (3-10 ms) and microsecond (200-20 $\mu \mathrm{s})$ dwell times, respectively, showing the predicted relationship between dwell time and size LODs for silver nanoparticles.

It should be mentioned that a signal-to-noise ratio approach has been followed for mass and size LOD estimations in agreement with the trend followed in SP-ICP-MS publications, and also because it allows a common approach for both pulse and transient signal events.

Alternative approaches followed in other fields (e.g., chromatography) based on the use of integrated signals could be applied to microsecond measurements, although they have not been considered here.

Whereas short dwell times are recommended when working with millisecond dwell times, the opposite is true when using microsecond dwell times. In both cases, the duration of the particle events limits the suitable dwell times. As a rule of thumb, dwell times longer than twice the duration of the events should be used when working at millisecond dwell times to record the particle events as pulses, whereas for microseconds, dwell times should be shorter that half the duration of the events. For these reasons, dwell times shorter than $3 \mathrm{~ms}$ and longer than $200 \mu$ s were not considered in figure 5, because those dwell times correspond to the boundary between both recording modes, recording particle events with 1 and 2 readings within the same run. Finally, the specific performance of the ICP-MS instrument plays a significant role on mass and size LODs through its detection efficiency and the duration of the particle events, which in turn depends on the plasma and the mass spectrometer operating conditions [48].

\subsection{Number concentration limit of detection}

If the criterion applied for discrimination of particles from baseline events guarantees that no particles are detected from a blank containing no particles (no false positives), the counting of particle events in a sample can be assimilated to an ideal Poisson counting process with zero blank, whose critical value is 0 and the minimum detection value can be rounded to 3 particle events [23]. The minimum detection value can be directly related to the number concentration limit of detection $\left(L O D_{\text {number }}\right)$ through equation 2 as [1]: 


$$
L O D_{\text {number }}=X_{D}^{\text {number }}=\frac{3}{\eta_{\text {neb }} Q_{\text {sam }} t_{i}}
$$

If particles are detected in the blank, the conventional expression for $\alpha=\beta=0.05$ an paired measurement (blank subtracted) can be used for calculation of the $L O D_{\text {number }}$ [23]:

$$
L O D_{\text {number }}=\frac{4.65 \sigma_{N, B}+2.71}{\eta_{\text {neb }} Q_{\text {sam }} t_{i}}
$$

where $\sigma_{N, B}$ is the standard deviation of the number of counted events $\left(Y_{N, B}\right)$. It can be calculated from a number of replicate blank measurements (e.g. 10) or estimated from the number of particles counted $\left(\sigma_{N, B}=\sqrt{Y_{N, B}}\right)$. If the LOD is just going to be used as a figure of merit, equation 13 could be simplify as:

$$
L O D_{\text {number }}=\frac{5 \sigma_{N, B}+3}{\eta_{n e b} Q_{\text {sam }} t_{i}}=\frac{5 \sqrt{Y_{N, B}}+3}{\eta_{\text {neb }} Q_{\text {sam }} t_{i}}
$$

If the discrimination criterion does not guarantee a small number of false positives (e.g., by using a 3-sigma criterion, as we have seen above), number concentration detection limits are going to degrade significantly, affecting to the detectability of particles over the size detection limit. In any case, number concentration limit of detection depends also on the sample introduction to the ICP-MS and the acquisition time, so it can be enhanced by improving nebulization efficiency, increasing the sample flow rate, and/or using longer acquisition times.

\section{Detection capability of dissolved element: Dissolved element mass concentration limit of detection}

In principle, baseline distributions follow Poisson profiles, which can be treated as Poissonnormal for mean values over ca. 5 counts. According to the conventional expression (equations S7 or S8 in supplementary material) for calculation of dissolved element mass concentration limit of detection $\left(L O D_{d i s}\right)$, the following parameters must be known: i) the standard deviation of the mean intensity of the baseline from a blank $\left(\sigma_{\bar{B}}\right)$ and ii) the corresponding sensitivity factor $(b)$. Since the sensitivity factor can be expressed in counts as $K_{R} t_{d w e l l}$ (equation 1 involves signals expressed in counts per second), the following expression can be derived:

$$
L O D_{\text {dis }}=X_{D}^{\text {dis }}=\frac{3 \sigma_{\bar{B}}}{K_{R} t_{d w e l l}}
$$

In the case of blank baseline distributions, despite its Poisson nature, their means can be considered normally distributed due to the central limit theorem, with $\sigma_{\bar{B}}=\sigma_{B} / \sqrt{m}$, where $m$ is the number of baseline readings. Therefore, limits of detection can be expressed as:

$$
L O D_{\text {dis }}=\frac{3 \sqrt{Y_{R, B}}}{K_{R} \sqrt{t_{i}}}
$$


considering $\sigma_{\bar{B}}=\sqrt{Y_{B}}=\sqrt{Y_{R, B} t_{d w e l l}}$, where $Y_{R, B}$ is the blank baseline intensity expressed in counts per second, and $m$ equal to the total number of readings $\left(=t_{i} / t_{d w e l l}\right)$, because in practice particle readings accounts for less than $5 \%$ of the total number of readings. $\sigma_{\bar{B}}$ can be calculated from a number of replicate baseline blank measurements (e.g. 10) or estimated from the baseline intensity $\left(Y_{R, B}\right)$.

Equation 16 reveals that the detection limits for the dissolved fraction are independent on the dwell time used and, for each isotope and a given baseline blank intensity, they just depend on the total acquisition time and hence the total number of counts accumulated during that time $\left(\Sigma Y_{B}\right)$, which ultimately controls the standard deviation of the blank baseline as the square root of the total number of counts. Although the evaluation of equation 16 would require a large number of replicates to confirm empirically the validity of the central limit theorem, table 1 shows experimental blank baseline standard deviations and detection limits achieved by using a feasible number of replicates (10) and dwell times from 20 to $100 \mu \mathrm{s}$. Results from table 1 confirms that, in spite of the dwell times span over almost an order of magnitude, limits of detection are in the same order. This is because the counts accumulated for the blank baselines during the acquisition time ( $60 \mathrm{~s}$ ) were similar for the three dwell times considered (ca. 2,200 counts) and hence their relative standard deviations (2.0-3.0\%) are in agreement with the expected one $(2.1 \%)$. This means that the detection capability for dissolved elements is not affected by the dwell time selected and it can be improved just by increasing the total acquisition time.

\section{Summary of critical values and limits of detection in SP-ICP-MS}

Table 2 summarizes the expressions proposed for the critical values and limits of detection involved in SP-ICP-MS methods. Whereas the critical values can be used as $a$ posteriori limits of decision in relation with the presence of particles and dissolved element in a sample, limits of detection are going to be used as a priori figures of merit of the methods. Their calculation requires to know the different theoretical and experimental parameters included in the denominators and the corresponding blank standard deviations. The term blank must be understood here in its widest sense, applying to both reagent and matrix blanks, leading to the respective instrumental and methodological critical values or limits of detection. Alternatively, the standard deviations can be estimated as the square root of the mean values involved $(\sigma=\sqrt{Y})$, because of the Poisson nature of the measurements. This later expression would not apply to mass per particle and particle size detection limits when the intensity of the baseline exceeds a certain value because of the additional contribution of the flicker noise, which can be considered as $\sigma_{B}=\sqrt{Y_{B}+\xi^{2} Y_{B}^{2}}$, where $\xi$ is the flicker noise coefficient [18]. The value of the flicker noise coefficient, as well as the signal intensity above which becomes 
significant depends on the detector. In our laboratory, using quadrupole ICP-MS instruments equipped with electron multipliers, flicker noise coefficients of 0.04 , which becomes relevant over ca. 10-100 counts, are typically obtained [18]. In the case of TOF-ICP-MS instruments, which are equipped with microchannel plate detectors, showing compound Poisson-distributed noise for low-count signals, the expressions must be adapted conveniently [19,20].

According to the approach presented in section 4.2, size and mass per particle limits of detection and critical values are calculated from the same expressions. In the case of number concentrations, the minimum limit of detection is given by equation 12 under conditions of no particles detected in the blanks. If particles are detected in the blanks, a $2.33 \sigma$ criterion must be applied for establishing the critical value to make the decision about the presence of particles, whereas a $5 \sigma+3$ criterion is applied for estimating the limit of detection. These criteria correspond to paired measurements (blanks subtracted) governed by Poisson statistics, which is the case when counting particles. With respect to the dissolved element, the mass concentration corresponding to the critical value and the limit of detection have been calculated considering the $1.64 \sigma$ and $3 \sigma$ criteria respectively, assuming that mean baseline blanks are well-known and follow normal distributions.

A calculation tool has been included as Supplementary Material to facilitate the estimation of SP-ICP-MS critical values and limits of detection for different elements and particle compositions. Table 3 summarizes size LODs for selected metal and oxide particles using a commercial quadrupole instrument equipped with a conventional sample introduction system (cyclonic spray chamber and concentric nebulizer) under typical experimental conditions (analyte transport efficiency: 5\%, sample flow rate: $0.4 \mathrm{~mL} \mathrm{~min}^{-1}$, dwell times: $5 \mathrm{~ms}$ and $100 \mu \mathrm{s}$, time-width of particle events: $500 \mu \mathrm{s}$ ). More than 50\% of the elements showed size LODs below $10 \mathrm{~nm}$, both for metallic and oxide nanoparticles, with LODs below $5 \mathrm{~nm}$ for some rare-earth oxides because of the low background levels and the high sensitivities attainable. With respect to the dissolved element concentration, LODs in the picogram per liter level, lower than using ICP-MS in standard mode, can be achieved because of total acquisition times used in SP-ICP-MS are in the range of minutes, whereas in standard mode individual isotopes are just monitored during seconds (e.g., $1 \mathrm{~s}$ when measuring at $50 \mathrm{~ms}$ dwell time and 20 sweeps). The increase in the acquisition time involves a proportional increase in the counts recorded, whereas the standard deviation increases with the square root of the signal, which results in LOD reduction proportional to the square root of the acquisition time. In any case, the LODs shown in table 3 are instrumental LODs and should be considered as the best-case scenario for SP-ICPMS analysis.

Table 4 shows minimum number concentration detection limits attainable with the sample introduction configurations listed, and calculated by using equation 12 . These LODs are 
in the range of 100-500 particles per $\mathrm{mL}$ for total acquisition times of one minute. As can be seen, improvements in analyte transport efficiency with pneumatic nebulization systems do not result in a reduction of LODs because of the lower sample flow rates required and the most suitable way of improving them is by increasing the acquisition time.

\section{Final remarks}

The unique features of SP-ICP-MS for the analysis of nanoparticles, along with its availability in commercial instruments, have led to the success of this technique and its increasing application in several fields (environment, toxicology, food...). However, SP-ICPMS still lacks of standardized metrological approaches, characteristic of mature analytical methods, to express and calculate its detection capabilities. In this respect, although the main trend in SP-ICP-MS is aimed at the detection of even smaller nanoparticles, we must not overlook that the technique is also able to detect such nanoparticles, as well as dissolved forms, at low number and mass concentrations, respectively. In each case, clear criteria and the corresponding mathematical expressions should be available and widely accepted to express the limits of detection in the different domains covered by SP-ICP-MS.

In a first stage, criteria and approaches from concentration LODs were applied in a straightforward way for the discrimination of particle events and the calculation of size LODs, whereas less attention was paid to number concentrations and dissolved element LODs. Based on our experience, application of conventional criteria is an oversimplification that does not respond to the peculiarities of the analytical signals in SP-ICP-MS. The discrete nature of the signals and the distributions involved, governed by Poisson statistics, introduce additional levels of complexity to their treatment that have been overlooked in many publications.

The present paper responds to a need of harmonizing approaches and criteria to express and calculate limits of detection in the different domains involved in SP-ICP-MS for validation purposes, together with the need of critical values or limits of decision to assess the presence of particles and/or dissolved species in any sample. The criteria applied for discrimination of particles from baseline events must be coherent not only with the estimation of size LODs, but also in relation to the attainable number concentration LODs, which means that the topic of detectability in SP-ICP-MS must be addressed under a holistic approach.

\section{Conflicts of interest}

There are no conflicts to declare.

\section{Acknowledgements}


This work was supported by the Spanish Ministry of Science, Innovation and Universities and the European Regional Development Fund, project RTI2018-096111B-I00 (MICINN/FEDER).

\section{Appendix A. Supplementary material}

Supplementary material to this article can be found online at $\cdot \mathrm{https}: / /$ doi.org/10.1016/j.sab.\#\#\#.\#\#.\#\#\#

\section{References}

[1] F. Laborda, E. Bolea, J. Jiménez-Lamana, Single particle inductively coupled plasma mass spectrometry: a powerful tool for nanoanalysis., Anal. Chem. 86 (2014) 2270-8. doi:10.1021/ac402980q.

[2] M.D. Montaño, J.W. Olesik, A.G. Barber, K. Challis, J.F. Ranville, Single Particle ICPMS: Advances toward routine analysis of nanomaterials, Anal. Bioanal. Chem. 408 (2016) 5053-5074. doi:10.1007/s00216-016-9676-8.

[3] C. Degueldre, P.-Y. Favarger, Colloid analysis by single particle inductively coupled plasma-mass spectroscopy: a feasibility study, Colloids Surfaces A Physicochem. Eng. Asp. 217 (2003) 137-142. doi:10.1016/S0927-7757(02)00568-X.

[4] F. Laborda, J. Jiménez-Lamana, E. Bolea, J.R. Castillo, Selective identification, characterization and determination of dissolved silver(i) and silver nanoparticles based on single particle detection by inductively coupled plasma mass spectrometry, J. Anal. At. Spectrom. 26 (2011) 1362-1371. doi:10.1039/c0ja00098a.

[5] H.E. Pace, N.J. Rogers, C. Jarolimek, V. a Coleman, C.P. Higgins, J.F. Ranville, Determining transport efficiency for the purpose of counting and sizing nanoparticles via single particle inductively coupled plasma mass spectrometry., Anal. Chem. 83 (2011) 9361-9. doi:10.1021/ac201952t.

[6] O. Borovinskaya, B. Hattendorf, M. Tanner, S. Gschwind, D. Günther, A prototype of a new inductively coupled plasma time-of-flight mass spectrometer providing temporally resolved, multi-element detection of short signals generated by single particles and droplets, J. Anal. At. Spectrom. 28 (2013) 226. doi:10.1039/c2ja30227f.

[7] A. Hineman, C. Stephan, Effect of dwell time on single particle inductively coupled 
plasma mass spectrometry data acquisition quality, J. Anal. At. Spectrom. 29 (2014) 1252-1257. doi:10.1039/c4ja00097h.

[8] P.N. Shaw, A. Donard, Nano-particle analysis using dwell times between $10 \mu$ s and $70 \mu \mathrm{s}$ with an upper counting limit of greater than $3 \times 107 \mathrm{cps}$ and a gold nanoparticle detection limit of less than 10nm diameter., J. Anal. At. Spectrom. (2016) 1234-1242. doi:10.1039/C6JA00047A.

[9] F. Laborda, E. Bolea, J. Jiménez-Lamana, Single particle inductively coupled plasma mass spectrometry for the analysis of inorganic engineered nanoparticles in environmental samples, Trends Environ. Anal. Chem. 9 (2016) 15-23. doi:10.1016/j.teac.2016.02.001.

[10] D. Mozhayeva, C. Engelhard, A critical review of single particle inductively coupled plasma mass spectrometry - A step towards an ideal method for nanomaterial characterization, J. Anal. At. Spectrom. (2019). doi:10.1039/c9ja00206e.

[11] M. Thompson, S.L.R. Ellison, Towards an uncertainty paradigm of detection capability, Anal. Methods. 5 (2013) 5857. doi:10.1039/c3ay41209a.

[12] M. Thompson, Do we really need detection limits?, Analyst. 123 (1998) 405-407. doi:10.1039/a705702d.

[13] L.A. Currie, Nomenclature in evaluation of analytical methods, including detect ion and quantification ca pa bi I it ies ' ( IUPAC Recommendations 1995 ), Pure Appl. Chem. 67 (1995) 1699-1723. doi:10.1016/S0003-2670(99)00104-X.

[14] ISO 11843-1:1997, Capability of detection - Part 1: Terms and definitions, in: International Standards Organisation, Geneva, 1997.

[15] D. Montville, E. Voigtman, Statistical properties of limit of detection test statistics, Talanta. 59 (2003) 461-476. doi:10.1016/S0039-9140(02)00574-X.

[16] L. V. Rajaković, D.D. Marković, V.N. Rajaković-Ognjanović, D.Z. Antanasijević, Review: The approaches for estimation of limit of detection for ICP-MS trace analysis of arsenic, Talanta. 102 (2012) 79-87. doi:10.1016/j.talanta.2012.08.016.

[17] F. Laborda, J. Jiménez-Lamana, E. Bolea, J.R. Castillo, Critical considerations for the determination of nanoparticle number concentrations, size and number size distributions by single particle ICP-MS, J. Anal. At. Spectrom. 28 (2013) 1220-1232. doi:10.1039/c3ja50100k.

[18] F. Laborda, A.C. Gimenez-Ingalaturre, E. Bolea, J.R. Castillo, Single particle inductively coupled plasma mass spectrometry as screening tool for detection of particles, Spectrochim. Acta Part B At. Spectrosc. 159 (2019) 105654. doi:10.1016/j.sab.2019.105654.

[19] A. Gundlach-Graham, L. Hendriks, K. Mehrabi, D. Günther, Monte Carlo Simulation of Low-Count Signals in Time-of-Flight Mass Spectrometry and Its Application to Single- 
[20] L. Hendriks, A. Gundlach-Graham, D. Günther, Performance of sp-ICP-TOFMS with signal distributions fitted to a compound Poisson model, J. Anal. At. Spectrom. 34 (2019) 1900-1909. doi:10.1039/C9JA00186G.

[21] M. Belter, A. Sajnóg, D. Barałkiewicz, Over a century of detection and quantification capabilities in analytical chemistry - Historical overview and trends, Talanta. 129 (2014) 606-616. doi:10.1016/j.talanta.2014.05.018.

[22] H. Evard, A. Kruve, I. Leito, Tutorial on estimating the limit of detection using LC-MS analysis, part I: Theoretical review, Anal. Chim. Acta. 942 (2016) 23-39. doi:10.1016/j.aca.2016.08.043.

[23] L.A. Currie, Limits for Qualitative Detection and Quantitative Determination: Application to Radiochemistry, Anal. Chem. 40 (1968) 586-593. doi:10.1021/ac60259a007.

[24] V. Geertsen, E. Barruet, F. Gobeaux, J.-L. Lacour, O. Taché, Contribution to Accurate Spherical Gold Nanoparticle Size Determination by Single-Particle Inductively Coupled Mass Spectrometry: A Comparison with Small-Angle X-ray Scattering, Anal. Chem. 90 (2018) 9742-9750. doi:10.1021/acs.analchem.8b01167.

[25] I. Abad-Álvaro, E. Peña-Vázquez, E. Bolea, P. Bermejo-Barrera, J.R. Castillo, F. Laborda, Evaluation of number concentration quantification by single-particle inductively coupled plasma mass spectrometry: microsecond vs. millisecond dwell times, Anal. Bioanal. Chem. 408 (2016) 5089-5097. doi:10.1007/s00216-016-9515-y.

[26] K. Newman, C. Metcalfe, J. Martin, H. Hintelmann, P. Shaw, A. Donard, Improved single particle ICP-MS characterization of silver nanoparticles at environmentally relevant concentrations, J. Anal. At. Spectrom. 31 (2016) 2069-2077. doi:10.1039/C6JA00221H.

[27] B. Franze, I. Strenge, C. Engelhard, Single particle inductively coupled plasma mass spectrometry: evaluation of three different pneumatic and piezo-based sample introduction systems for the characterization of silver nanoparticles, J. Anal. At. Spectrom. 27 (2012) 1074-1083. doi:10.1039/c2ja00003b.

[28] Y. Dan, H. Shi, C. Stephan, X. Liang, Rapid analysis of titanium dioxide nanoparticles in sunscreens using single particle inductively coupled plasma-mass spectrometry, Microchem. J. 122 (2015) 119-126. doi:10.1016/j.microc.2015.04.018.

[29] Y. Dan, X. Ma, W. Zhang, K. Liu, C. Stephan, H. Shi, Single particle ICP-MS method development for the determination of plant uptake and accumulation of $\mathrm{CeO} 2$ nanoparticles, Anal. Bioanal. Chem. (2016) 5157-5167. doi:10.1007/s00216-016-95651. 
[30] I. Kálomista, A. Kéri, G. Galbács, On the applicability and performance of the single particle ICP-MS nano-dispersion characterization method in cases complicated by spectral interferences, J. Anal. At. Spectrom. 31 (2016) 1112-1122. doi:10.1039/C5JA00501A.

[31] J. Vidmar, R. Milačič, J. Ščančar, Sizing and simultaneous quantification of nanoscale titanium dioxide and a dissolved titanium form by single particle inductively coupled plasma mass spectrometry, Microchem. J. 132 (2017) 391-400. doi:10.1016/j.microc.2017.02.030.

[32] E. Bolea-Fernandez, D. Leite, A. Rua-Ibarz, L. Balcaen, M. Aramendía, M. Resano, F. Vanhaecke, Characterization of $\mathrm{SiO} 2$ nanoparticles by single particle-inductively coupled plasma-tandem mass spectrometry (SP-ICP-MS/MS), J. Anal. At. Spectrom. 32 (2017) 2140-2152. doi:10.1039/c7ja00138j.

[33] J. Liu, K.E. Murphy, R.I. MacCuspie, M.R. Winchester, Capabilities of single particle inductively coupled plasma mass spectrometry for the size measurement of nanoparticles: a case study on gold nanoparticles., Anal. Chem. 86 (2014) 3405-14. doi:10.1021/ac403775a.

[34] A.R. Donovan, C.D. Adams, Y. Ma, C. Stephan, T. Eichholz, H. Shi, Single particle ICP-MS characterization of titanium dioxide, silver, and gold nanoparticles during drinking water treatment, Chemosphere. 144 (2016) 148-153. doi:10.1016/j.chemosphere.2015.07.081.

[35] A.R. Donovan, C.D. Adams, Y. Ma, C. Stephan, T. Eichholz, H. Shi, Detection of zinc oxide and cerium dioxide nanoparticles during drinking water treatment by rapid single particle ICP-MS methods, Anal. Bioanal. Chem. 408 (2016) 5137-5145. doi:10.1007/s00216-016-9432-0.

[36] C. Degueldre, P.-Y. Favarger, C. Bitea, Zirconia colloid analysis by single particle inductively coupled plasma-mass spectrometry, Anal. Chim. Acta. 518 (2004). doi:10.1016/j.aca.2004.04.015.

[37] C. Degueldre, P.-Y. Favarger, R. Rossé, S. Wold, Uranium colloid analysis by single particle inductively coupled plasma-mass spectrometry., Talanta. 68 (2006) 623-8. doi:10.1016/j.talanta.2005.05.006.

[38] C. Degueldre, P. Favarger, S. Wold, Gold colloid analysis by inductively coupled plasma-mass spectrometry in a single particle mode, Anal. Chim. Acta. 555 (2006) 263268. doi:10.1016/j.aca.2005.09.021.

[39] S. Gschwind, L. Flamigni, J. Koch, O. Borovinskaya, S. Groh, K. Niemax, D. Günther, Capabilities of inductively coupled plasma mass spectrometry for the detection of nanoparticles carried by monodisperse microdroplets, J. Anal. At. Spectrom. 26 (2011) 1166-1174. doi:10.1039/c0ja00249f. 
[40] H.E. Pace, N.J. Rogers, C. Jarolimek, V. a Coleman, E.P. Gray, C.P. Higgins, J.F. Ranville, Single particle inductively coupled plasma-mass spectrometry: a performance evaluation and method comparison in the determination of nanoparticle size., Environ. Sci. Technol. 46 (2012) 12272-80. doi:10.1021/es301787d.

[41] D.M. Mitrano, A. Barber, A. Bednar, P. Westerhoff, C.P. Higgins, J.F. Ranville, Silver nanoparticle characterization using single particle ICP-MS (SP-ICP-MS) and asymmetrical flow field flow fractionation ICP-MS (AF4-ICP-MS), J. Anal. At. Spectrom. 27 (2012) 1131. doi:10.1039/c2ja30021d.

[42] S. Lee, X. Bi, R.B. Reed, J.F. Ranville, P. Herckes, P. Westerhoff, Nanoparticle size detection limits by single particle ICP-MS for 40 elements., Environ. Sci. Technol. 48 (2014) 10291-300. doi:10.1021/es502422v.

[43] J. Tuoriniemi, G. Cornelis, M. Hassellöv, Size Discrimination and Detection Capabilities of Single-Particle ICPMS for Environmental Analysis of Silver Nanoparticles., Anal. Chem. 84 (2012) 3965-72. doi:10.1021/ac203005r.

[44] J. Jiménez-Lamana, I. Abad-Álvaro, K. Bierla, F. Laborda, J. Szpunar, R. Lobinski, Detection and characterization of biogenic selenium nanoparticles in selenium-rich yeast by single particle ICPMS, J. Anal. At. Spectrom. 33 (2018) 452-460. doi:10.1039/C7JA00378A.

[45] M.V. Taboada-López, N. Alonso-Seijo, P. Herbello-Hermelo, P. Bermejo-Barrera, A. Moreda-Piñeiro, Determination and characterization of silver nanoparticles in bivalve molluses by ultrasound assisted enzymatic hydrolysis and sp-ICP-MS, Microchem. J. 148 (2019) 652-660. doi:10.1016/J.MICROC.2019.05.023.

[46] A.K. Venkatesan, R.B. Reed, S. Lee, X. Bi, D. Hanigan, Y. Yang, J.F. Ranville, P. Herckes, P. Westerhoff, Detection and Sizing of Ti-Containing Particles in Recreational Waters Using Single Particle ICP-MS, Bull. Environ. Contam. Toxicol. 100 (2018) 120 126. doi:10.1007/s00128-017-2216-1.

[47] L.A. Currie, On the detection of rare, and moderately rare, nuclear events, J. Radioanal. Nucl. Chem. 276 (2008) 285-297. doi:10.1007/s10967-008-0501-5.

[48] E. Bolea-Fernandez, D. Leite, A. Rua-Ibarz, T. Liu, G. Woods, M. Aramendia, M. Resano, F. Vanhaecke, On the effect of using collision/reaction cell (CRC) technology in single-particle ICP-mass spectrometry (SP-ICP-MS), Anal. Chim. Acta. 1077 (2019) 95-106. doi:10.1016/j.aca.2019.05.077. 


\section{Glossary}

A

$b$

$d$

$F_{P}$

$K_{d}$

$K_{I C P M S}$

$K_{\text {intro }}$

$K_{M}$

$K_{m}$

$K_{N}$

$K_{R}$

$L O D$

$L O D_{d i s}$

$L O D_{\text {mass }}$

$L O D_{\text {number }}$ number concentration limit of detection

$L O D_{\text {size }} \quad$ size limit of detection

$N_{A v}$

Avogadro number

$M_{M}$

atomic mass of element $\mathrm{M}$

$m \quad$ number of baseline readings

$m_{P} \quad$ mass of element per particle

$n \quad$ threshold coefficient

$Q_{\text {sam }}$

$S$

$S_{C}$

$S_{D}$

$S_{\bar{D}}$

$S_{P}$

$S_{P_{i}}$

$S_{P_{\max }}$

$t_{d w e l l}$

$t_{i}$

$w$

$X_{C}$

sample introduction flow rate

net signal $\left(Y-Y_{B}\right)$

net critical value

net minimum detectable value

net mean intensity of a baseline

net intensity of a particle event

individual net intensity record along a transient particle event

maximum net intensity of a transient particle event

dwell time

acquisition time

base width of a transient particle event

concentration critical value or limit of decision 
$X_{C}^{\operatorname{mass}} \quad$ mass per particle critical value

$X_{C}^{\text {size }} \quad$ size critical value

$X_{C}^{\text {number }}$ number concentration critical value

$X_{C}^{\text {dis }} \quad$ dissolved element mass concentration critical value

$X_{D} \quad$ limit of detection

$X_{D}^{\text {mass }} \quad$ mass per particle limit of detection

$X_{D}^{\text {size }} \quad$ size limit of detection

$X_{D}^{\text {number }}$ number concentration limit of detection

$X_{D}^{\text {dis }} \quad$ dissolved element mass concentration limit of detection

$X^{N} \quad$ particle number concentration

$X^{M} \quad$ mass concentration

$X^{D}$

mass concentration of dissolved element

signal

blank signal or mean intensity of a blank baseline

critical value

minimum detectable value

gross mean intensity of a baseline

number of particle events

mean number of events counted in blanks

mean blank baseline intensity expressed as count rate

total blank baseline number of counts recorded during the acquisition time $t_{i}$

ICP-MS signal expressed in counts per time unit

probability of false positive

probability of false negative

threshold security term

analyte transport efficiency

flicker noise coefficient

particle density

standard deviation

standard deviation of a blank signal $Y_{B}$

standard deviation of the mean intensity of blank baselines

standard deviation of the number of particles events in blanks $Y_{N, B}$ 
Table 1. Theoretical and experimental dissolved element mass concentration limits of detection $\left(L O D_{\text {dis }}\right)$ for silver $\left({ }^{107} \mathrm{Ag}\right)$ measured in SP-ICP-MS mode at different dwell times. Total acquisition time: $60 \mathrm{~s}$. Number of replicates: 10 .

\begin{tabular}{|c|c|c|c|c|c|c|c|c|}
\hline $\begin{array}{l}\text { dwell } \\
\text { time }\end{array}$ & $\begin{array}{l}\text { number of } \\
\text { readings }\end{array}$ & cps & counts & counts & $R S D_{\bar{B}}$ & $\operatorname{cps}\left(\mu \mathrm{g} \mathrm{L}^{-1}\right)^{-1}$ & $\begin{array}{c}\mathrm{LOD}_{\text {dis }} \\
\text { theoretical } \\
\mathrm{ng} \mathrm{L^{-1 }}\end{array}$ & $\begin{array}{c}\mathrm{LOD}_{\mathrm{dis}} \\
\text { experimental } \\
\mathrm{ng} \mathrm{\textrm {L } ^ { - 1 }}\end{array}$ \\
\hline \multicolumn{9}{|l|}{$\mu \mathrm{s}$} \\
\hline 100 & 600000 & $36 \pm 1$ & $2160 \pm 60$ & $1.07 \times 10^{-4}$ & 2.97 & $8.95 \times 10^{4}$ & 0.026 & 0.036 \\
\hline 50 & 1200000 & $38 \pm 1$ & $2280 \pm 60$ & $3.87 \times 10^{-5}$ & 2.04 & $9.01 \times 10^{4}$ & 0.026 & 0.026 \\
\hline 20 & 3000000 & $38 \pm 1$ & $2280 \pm 60$ & $2.12 \times 10^{-5}$ & 2.79 & $9.03 \times 10^{4}$ & 0.026 & 0.035 \\
\hline
\end{tabular}


Table 2. Expressions for the critical values and limits of detection in SP-ICP-MS.

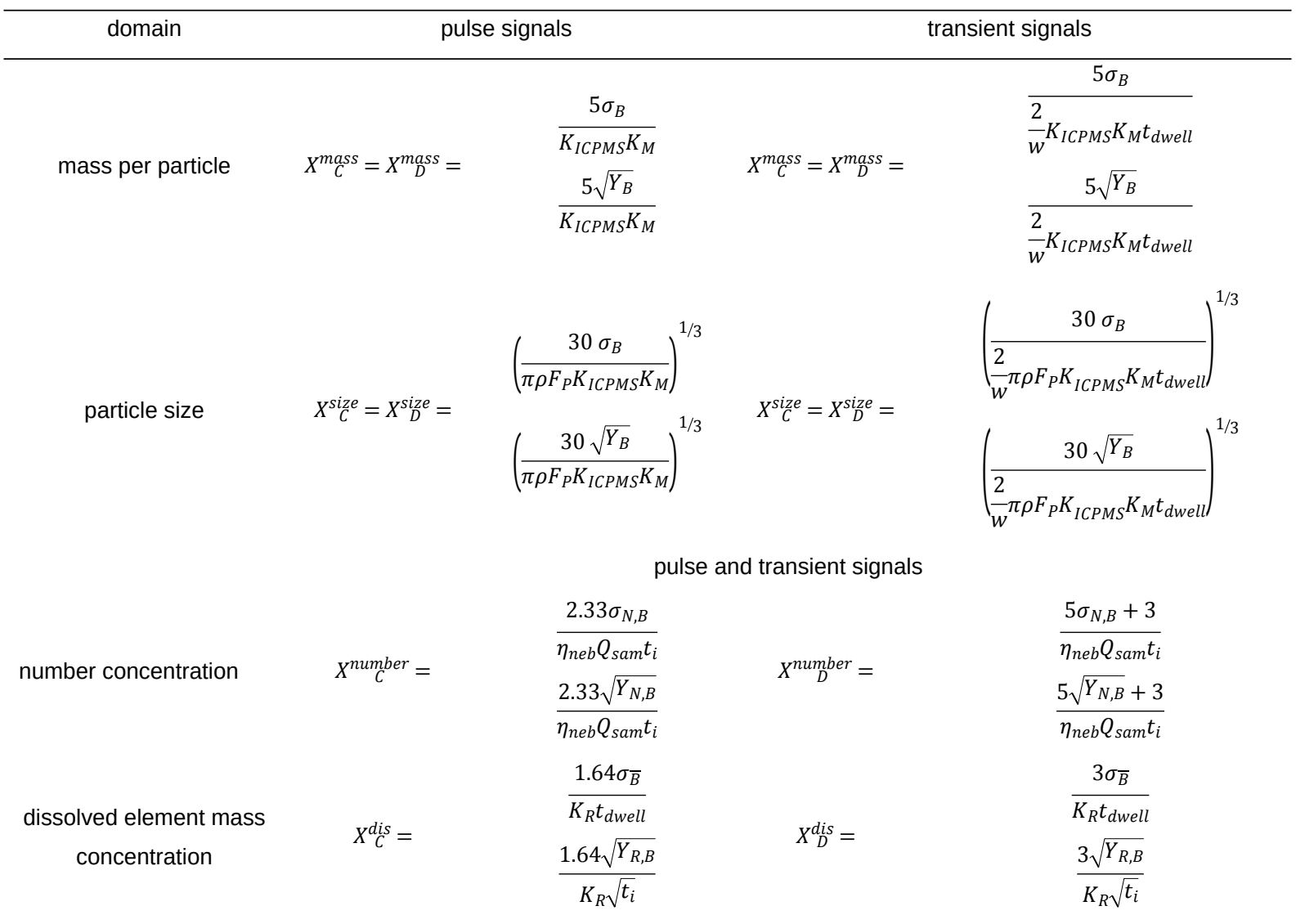


Table 3. Particle size and dissolved element mass concentration LODs.

\begin{tabular}{|c|c|c|c|c|c|c|c|}
\hline \multirow[t]{2}{*}{ element } & \multirow[t]{2}{*}{ isotope } & \multirow[t]{2}{*}{ particle composition } & \multirow[t]{2}{*}{$\begin{array}{c}\mathrm{K}_{\mathrm{R}}^{(\mathrm{a})} \\
\operatorname{cps}\left(\mu \mathrm{L} \mathrm{L}^{-1}\right)^{-1}\end{array}$} & \multirow[t]{2}{*}{$\begin{array}{c}Y_{R, B}(a) \\
c p s\end{array}$} & \multicolumn{2}{|c|}{$\begin{array}{c}\text { LOD }_{\text {size }}{ }^{(b)} \\
n m\end{array}$} & $\begin{array}{c}\text { LOD }_{\text {dis }}(\mathrm{d}) \\
\mathrm{ng} \mathrm{L}^{-1}\end{array}$ \\
\hline & & & & & $\mathrm{t}_{\mathrm{dwell}}=5 \mathrm{~ms}$ & $\mathrm{t}_{\mathrm{dwell}}=100 \mu \mathrm{s}^{(\mathrm{c})}$ & \\
\hline $\mathrm{Ag}$ & 107 & $\mathrm{Ag}$ & 62644 & 203 & 17.4 & 12.3 & 0.09 \\
\hline Al & 27 & Al & 140231 & 1771 & 29.9 & 21.2 & 0.1 \\
\hline & & $\mathrm{Al}_{2} \mathrm{O}_{3}$ & & & 32.6 & 23.0 & \\
\hline As & 75 & As & 10876 & 24 & 26.7 & 18.9 & 0.2 \\
\hline & & $\mathrm{As}_{2} \mathrm{O}_{3}$ & & & 33.7 & 23.9 & \\
\hline $\mathrm{Au}$ & 197 & $\mathrm{Au}$ & 27343 & 21 & 12.7 & 9.0 & 0.06 \\
\hline B & 11 & $\mathrm{~B}$ & 26333 & 4745 & 60.3 & 42.7 & 1.0 \\
\hline & & $\mathrm{B}_{2} \mathrm{O}_{3}$ & & & 93.8 & 66.3 & \\
\hline $\mathrm{Ba}$ & 137 & $\mathrm{Ba}$ & 22924 & 34 & 26.0 & 18.4 & 0.1 \\
\hline & & $\mathrm{BaSO}_{4}$ & & & 28.6 & 20.2 & \\
\hline $\mathrm{Be}$ & 9 & $\mathrm{Be}$ & 15758 & 1 & 18.6 & 13.1 & 0.02 \\
\hline $\mathrm{Bi}$ & 209 & $\mathrm{Bi}$ & 131040 & 15 & 9.0 & 6.3 & 0.01 \\
\hline & & $\mathrm{Bi}_{2} \mathrm{O}_{3}$ & & & 9.6 & 6.8 & \\
\hline $\mathrm{Ca}$ & 44 & $\mathrm{Ca}$ & 147864 & 11780 & 48.5 & 34.3 & 0.3 \\
\hline & & $\mathrm{CaO}$ & & & 42.0 & 29.7 & \\
\hline & & $\mathrm{CaCO}_{3}$ & & & 54.6 & 38.6 & \\
\hline $\mathrm{Cd}$ & 111 & $\mathrm{Cd}$ & 14972 & 2 & 14.1 & 10.0 & 0.04 \\
\hline & & CdSe & & & 19.3 & 13.6 & \\
\hline $\mathrm{Ce}$ & 140 & $\mathrm{Ce}$ & 108913 & 7 & 9.6 & 6.8 & 0.01 \\
\hline & & $\mathrm{CeO}_{2}$ & & & 9.8 & 7.0 & \\
\hline Co & 59 & Co & 103622 & 270 & 16.2 & 11.5 & 0.06 \\
\hline & & $\mathrm{CoO}$ & & & 19.6 & 13.9 & \\
\hline & & $\mathrm{Co}_{3} \mathrm{O}_{4}$ & & & 20.4 & 14.4 & \\
\hline $\mathrm{Cr}$ & 52 & $\mathrm{Cr}$ & 89534 & 84751 & 47.8 & 33.8 & 1.3 \\
\hline & & $\mathrm{Cr}_{2} \mathrm{O}_{3}$ & & & 60.3 & 42.6 & \\
\hline $\mathrm{Cu}$ & 65 & $\mathrm{Cu}$ & 26502 & 58 & 19.7 & 14.0 & 0.1 \\
\hline & & $\mathrm{CuO}$ & & & 24.2 & 17.1 & \\
\hline Dy & 163 & Dy & 37892 & 0.1 & 6.1 & 4.3 & 0.003 \\
\hline & & $\mathrm{Dy}_{2} \mathrm{O}_{3}$ & & & 6.6 & 4.7 & \\
\hline $\mathrm{Er}$ & 166 & Er & 51046 & 0.1 & 5.5 & 3.9 & 0.002 \\
\hline & & $\mathrm{Er}_{2} \mathrm{O}_{3}$ & & & 5.8 & 4.1 & \\
\hline $\mathrm{Eu}$ & 153 & $\mathrm{Eu}$ & 74744 & 0.3 & 6.9 & 4.9 & 0.003 \\
\hline & & $\mathrm{Eu}_{2} \mathrm{O}_{3}$ & & & 6.5 & 4.6 & \\
\hline Gd & 157 & $\mathrm{Gd}$ & 30872 & 0.1 & 6.7 & 4.8 & 0.004 \\
\hline & & $\mathrm{Gd}_{2} \mathrm{O}_{3}$ & & & 7.2 & 5.1 & \\
\hline $\mathrm{Hf}$ & 180 & $\mathrm{Hf}$ & 54727 & 2 & 7.6 & 5.4 & 0.009 \\
\hline & & $\mathrm{HfO}_{2}$ & & & 9.0 & 6.3 & \\
\hline $\mathrm{Hg}$ & 5 & $\mathrm{Hg}$ & 2209 & 98 & 43.0 & 30.4 & 1.7 \\
\hline Ho & 165 & Ho & 149531 & 0.1 & 3.8 & 2.7 & 0.001 \\
\hline & & $\mathrm{Ho}_{2} \mathrm{O}_{3}$ & & & 4.1 & 2.9 & \\
\hline In & 115 & In & 171019 & 6 & 7.7 & 5.4 & 0.005 \\
\hline & & $\ln _{2} \mathrm{O}_{3}$ & & & 8.2 & 5.8 & \\
\hline & & $\operatorname{In}(\mathrm{OH})_{3}$ & & & 10.3 & 7.3 & \\
\hline Ir & 193 & Ir & 79601 & 4 & 6.5 & 4.6 & 0.01 \\
\hline La & 139 & $\mathrm{La}$ & 568165 & 2.1 & 4.6 & 3.3 & 0.001 \\
\hline & & $\mathrm{La}_{2} \mathrm{O}_{3}$ & & & 4.8 & 3.4 & \\
\hline $\mathrm{Li}$ & 7 & $\mathrm{Li}$ & 62259 & 85 & 40.6 & 28.7 & 0.06 \\
\hline Lu & 175 & Lu & 152549 & 0.1 & 3.7 & 2.6 & 0.001 \\
\hline & & $\mathrm{Lu}_{2} \mathrm{O}_{3}$ & & & 3.9 & 2.8 & \\
\hline $\mathrm{Mg}$ & 24 & $\mathrm{Mg}$ & 188923 & 4782 & 37.0 & 26.2 & 0.1 \\
\hline & & $\mathrm{MgO}$ & & & 33.6 & 23.8 & \\
\hline $\mathrm{Mn}$ & 55 & $\mathrm{Mn}$ & 146823 & 1181 & 19.6 & 13.9 & 0.09 \\
\hline & & $\mathrm{Mn}_{2} \mathrm{O}_{3}$ & & & 26.2 & 18.5 & \\
\hline Mo & 95 & Mo & 19064 & 3 & 12.7 & 9.0 & 0.03 \\
\hline & & $\mathrm{MoO}_{3}$ & & & 18.8 & 13.3 & \\
\hline $\mathrm{Na}$ & 23 & $\mathrm{Na}$ & 210199 & 47730 & 63.7 & 45.0 & 0.4 \\
\hline $\mathrm{Nd}$ & 143 & $\mathrm{Nd}$ & 15940 & 0.9 & 12.8 & 9.0 & 0.02 \\
\hline & & $\mathrm{Nd}_{2} \mathrm{O}_{3}$ & & & 13.1 & 9.3 & \\
\hline $\mathrm{Ni}$ & 60 & $\mathrm{Ni}$ & 21914 & 36 & 19.5 & 13.8 & 0.1 \\
\hline & & $\mathrm{NiO}$ & & & 23.3 & 16.5 & \\
\hline $\mathrm{Pb}$ & 208 & $\mathrm{~Pb}$ & 80277 & 175 & 15.2 & 10.7 & 0.06 \\
\hline & & $\mathrm{PbO}$ & & & 16.5 & 11.7 & \\
\hline $\mathrm{Pd}$ & 105 & $\mathrm{Pd}$ & 30498 & 5 & 11.4 & 8.1 & 0.03 \\
\hline $\mathrm{Pr}$ & 141 & $\mathrm{Pr}$ & 131954 & 0.9 & 6.3 & 4.5 & 0.003 \\
\hline & & $\mathrm{Pr}_{6} \mathrm{O}_{11}$ & & & 6.8 & 4.8 & \\
\hline $\mathrm{Pt}$ & 195 & $\mathrm{Pt}$ & 24533 & 0 & 5.3 & 3.7 & 0.005 \\
\hline $\mathrm{Rh}$ & 103 & $\mathrm{Rh}$ & 157201 & 2 & 5.7 & 4.0 & 0.004 \\
\hline & & $\mathrm{Rh}_{2} \mathrm{O}_{3}$ & & & 7.0 & 4.9 & \\
\hline $\mathrm{Ru}$ & 101 & $\mathrm{Ru}$ & 26899 & 2 & 9.7 & 6.9 & 0.02 \\
\hline & & $\mathrm{RuO}_{2}$ & & & 12.9 & 9.1 & \\
\hline $\mathrm{Sb}$ & 121 & $\mathrm{Sb}$ & 33214 & 8 & 14.6 & 10.3 & 0.03 \\
\hline & & $\mathrm{Sb}_{2} \mathrm{O}_{3}$ & & & 16.7 & 11.8 & \\
\hline & & $\mathrm{Sb}_{2} \mathrm{O}_{5}$ & & & 19.3 & 13.6 & \\
\hline Sc & 45 & $\mathrm{Sc}$ & 80869 & 2507 & 36.6 & 25.9 & 0.2 \\
\hline & & $\mathrm{Sc}_{2} \mathrm{O}_{3}$ & & & 38.8 & 27.4 & \\
\hline $\mathrm{Se}$ & 82 & $\mathrm{Se}$ & 1816 & 194 & 72.8 & 51.5 & 3.0 \\
\hline $\mathrm{Si}$ & 29 & $\mathrm{Si}$ & 10969 & 120537 & 148.5 & 105.0 & 12.3 \\
\hline
\end{tabular}


(a) Ultrapure water.

\begin{tabular}{|c|c|c|c|c|}
\hline & & 183.3 & 129.6 & \\
\hline \multirow[t]{2}{*}{19342} & 0.9 & 11.6 & 8.2 & 0.02 \\
\hline & & 12.2 & 8.6 & \\
\hline \multirow[t]{2}{*}{40690} & 257 & 23.5 & 16.6 & 0.2 \\
\hline & & 25.9 & 18.3 & \\
\hline \multirow[t]{2}{*}{174518} & 264 & 20.7 & 14.6 & 0.04 \\
\hline & & 22.1 & 15.6 & \\
\hline \multirow[t]{2}{*}{153955} & 0.1 & 3.9 & 2.8 & 0.001 \\
\hline & & 4.3 & 3.0 & \\
\hline \multirow[t]{2}{*}{3237} & 1 & 22.0 & 15.6 & 0.1 \\
\hline & & 24.5 & 17.3 & \\
\hline \multirow[t]{2}{*}{8757} & 43 & 34.0 & 24.1 & 0.3 \\
\hline & & 41.4 & 29.3 & \\
\hline \multirow[t]{2}{*}{112528} & 12 & 8.6 & 6.1 & 0.01 \\
\hline & & 9.4 & 6.6 & \\
\hline \multirow[t]{2}{*}{157368} & 0.3 & 4.5 & 3.2 & 0.001 \\
\hline & & 4.8 & 3.4 & \\
\hline \multirow[t]{2}{*}{109688} & 441 & 19.6 & 13.9 & 0.07 \\
\hline & & 24.1 & 17.0 & \\
\hline \multirow[t]{2}{*}{107231} & 5 & 10.4 & 7.3 & 0.008 \\
\hline & & 10.8 & 7.6 & \\
\hline \multirow[t]{2}{*}{25406} & 0.2 & 8.4 & 6.0 & 0.007 \\
\hline & & 8.0 & 5.7 & \\
\hline \multirow[t]{2}{*}{35387} & 1479 & 33.3 & 23.5 & 0.4 \\
\hline & & 38.7 & 27.4 & \\
\hline
\end{tabular}

(b) Quadrupole ICP-MS. Analyte transport efficiency: 5\% (cyclonic spray chamber and concentric nebulizer), sample flow rate: $0.4 \mathrm{~mL} \mathrm{~min}^{-1}$.

(c) Time-width of particle events: $500 \mu \mathrm{s}$.

(d) Total acquisition time: $60 \mathrm{~s}$. 
Table 4. Number concentration LODs for different commercial sample introduction configurations.

\begin{tabular}{|c|c|c|c|}
\hline sample introduction system & $\begin{array}{c}\eta_{\text {neb }} \\
\%\end{array}$ & $\begin{array}{c}\mathrm{Q}_{\mathrm{sam}} \\
\mathrm{mL} \mathrm{min}^{-1}\end{array}$ & $\underset{L^{-1}}{\operatorname{LOD}_{\text {number }}{ }^{(a)}}$ \\
\hline $\begin{array}{l}\text { cyclonic spray chamber }+ \\
\text { concentric nebulizer (Glass Expansion) }\end{array}$ & 2.6 & 1.1 & $1.0 \times 10^{5}$ \\
\hline $\begin{array}{l}\text { baffled cyclonic spray chamber + } \\
\text { concentric nebulizer (Meinhard) }\end{array}$ & 5.3 & 0.4 & $1.4 \times 10^{5}$ \\
\hline $\begin{array}{c}\text { Asperon spray chamber }+ \\
\text { high efficiency nebulizer (Meinhard) }\end{array}$ & 37.7 & 0.016 & $4.9 \times 10^{5}$ \\
\hline
\end{tabular}

(a) Total acquisition time: $60 \mathrm{~s}$. 
Figure 3. Discrete Poisson baseline distributions for mean baseline intensities of (a) 0.001 , (b) 0.01 , (c) 0.1 (d) 1 and (e) 10 counts, with $10^{4}$ (green), $10^{5}$ (orange) and $10^{6}$ (blue) readings.

Figure 4. Detection of $97 \mathrm{~nm}$ silver nanoparticles under conditions where $\operatorname{LOD}_{\text {size }}=91 \mathrm{~nm}$ (Ag(I): $\left.2 \mu \mathrm{g} \mathrm{L}^{-1}\right)$. LOD criterion: $Y_{D}=Y_{C}=Y_{B}+5 \sigma$ (gray area in inset).

Figure 5. Experimental variation of size LODs with respect to dwell time at milliseconds (a) and microseconds (b) for silver nanoparticles. 

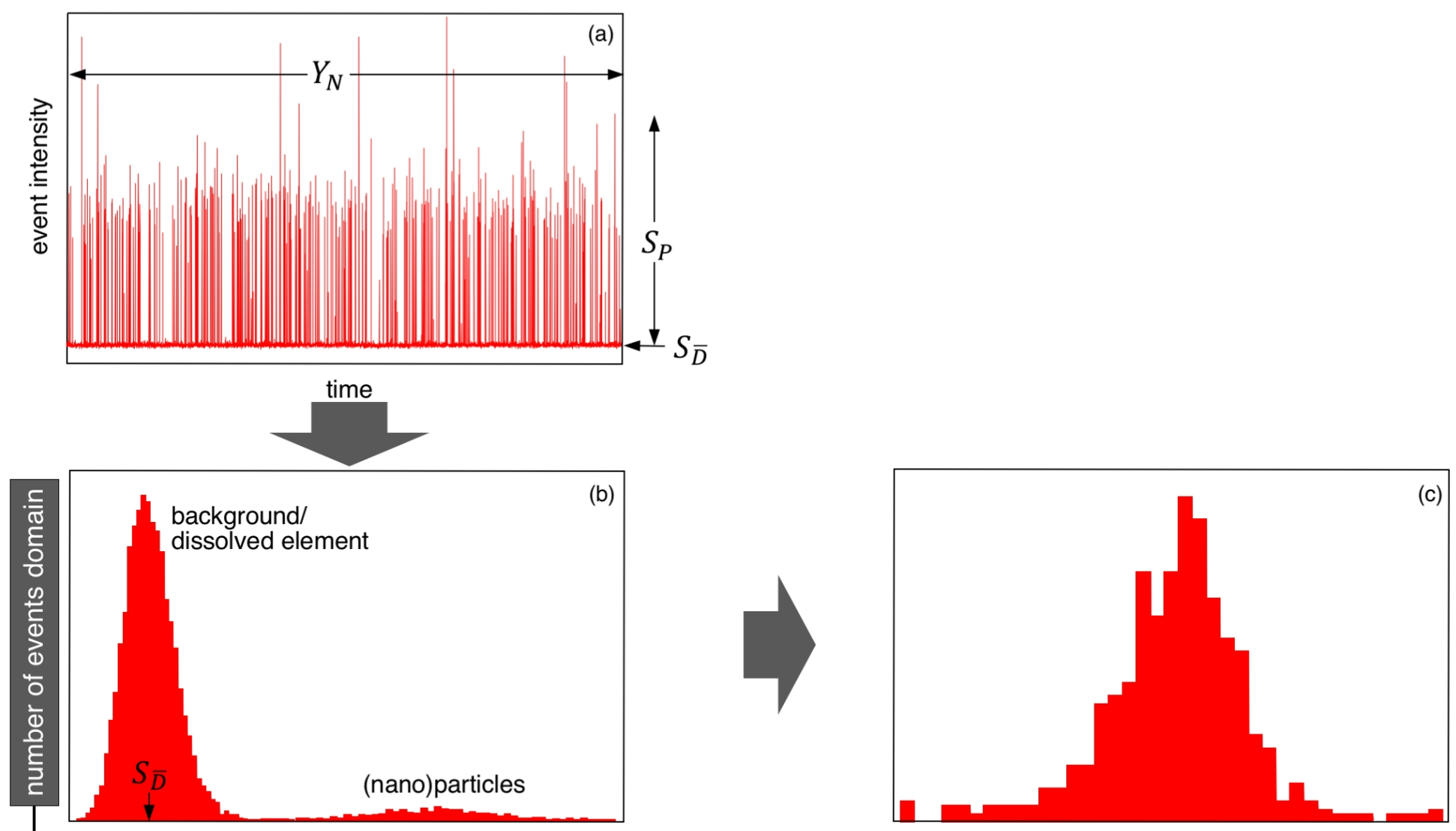

event intensity

domain (baseline) domain (particles) $\quad S_{P}=\frac{1}{6} \pi \rho F_{P} K_{I C P M S} K_{M} d^{3}$

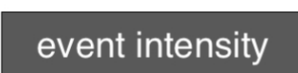

domain (particles)

$S_{P}=K_{I C P M S} K_{M} m_{P}$

element mass per particle domain

size domain

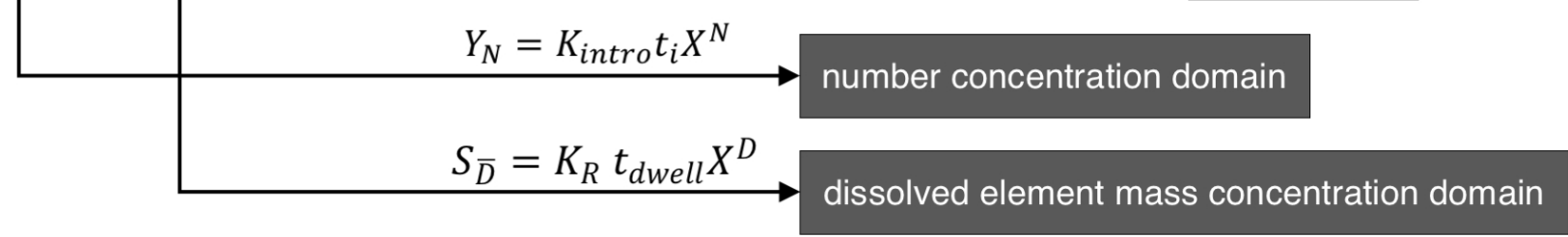




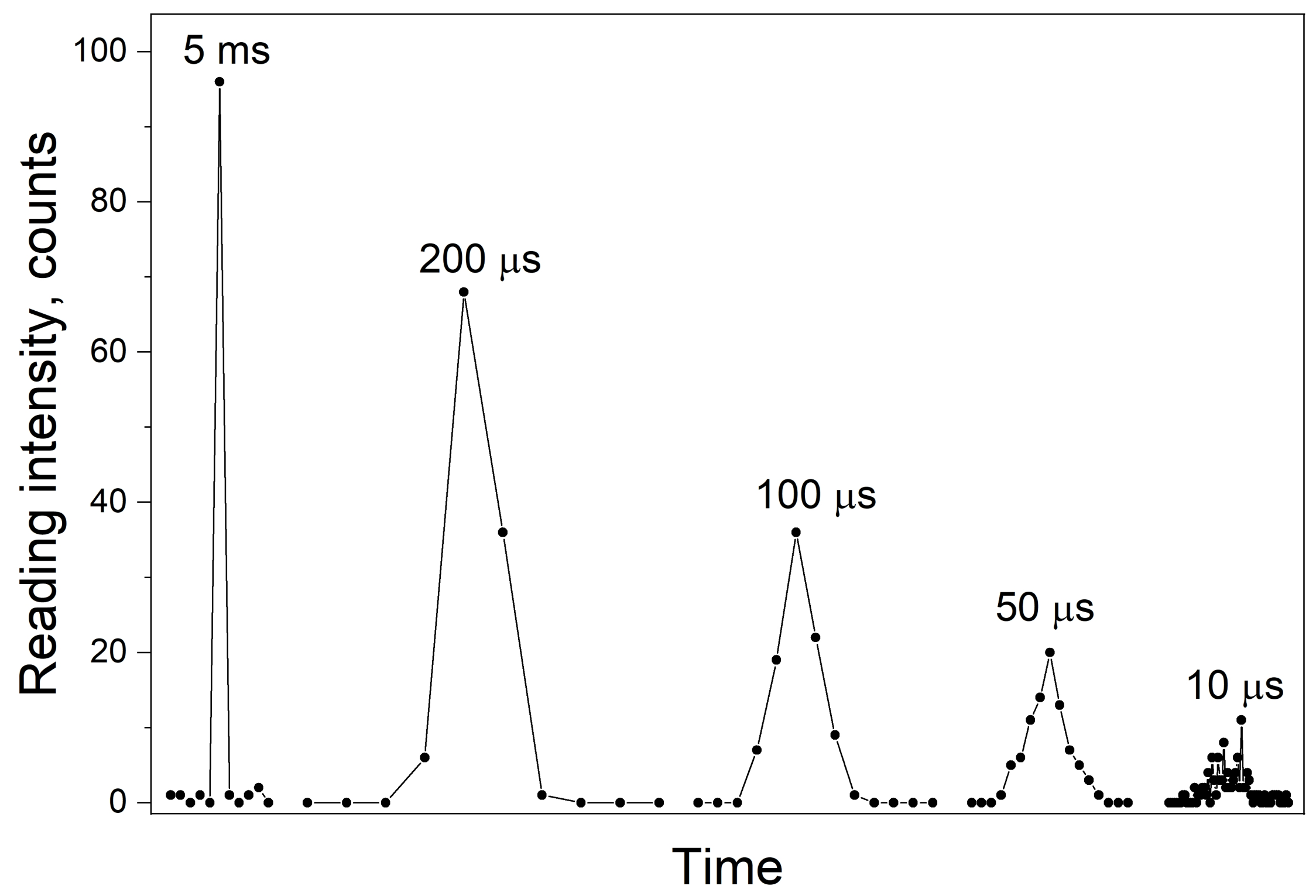



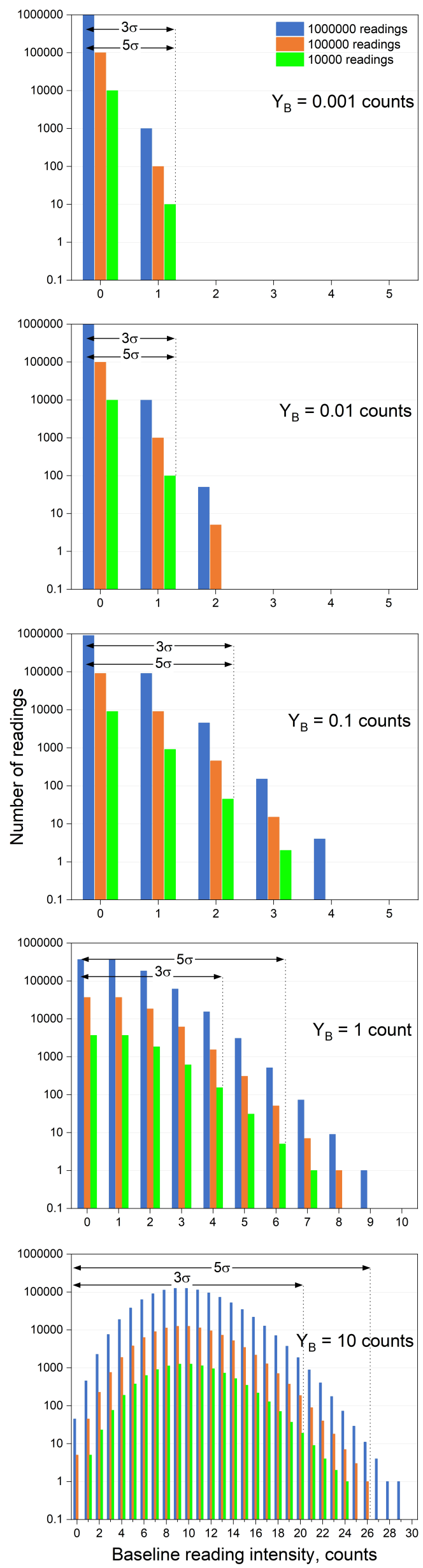

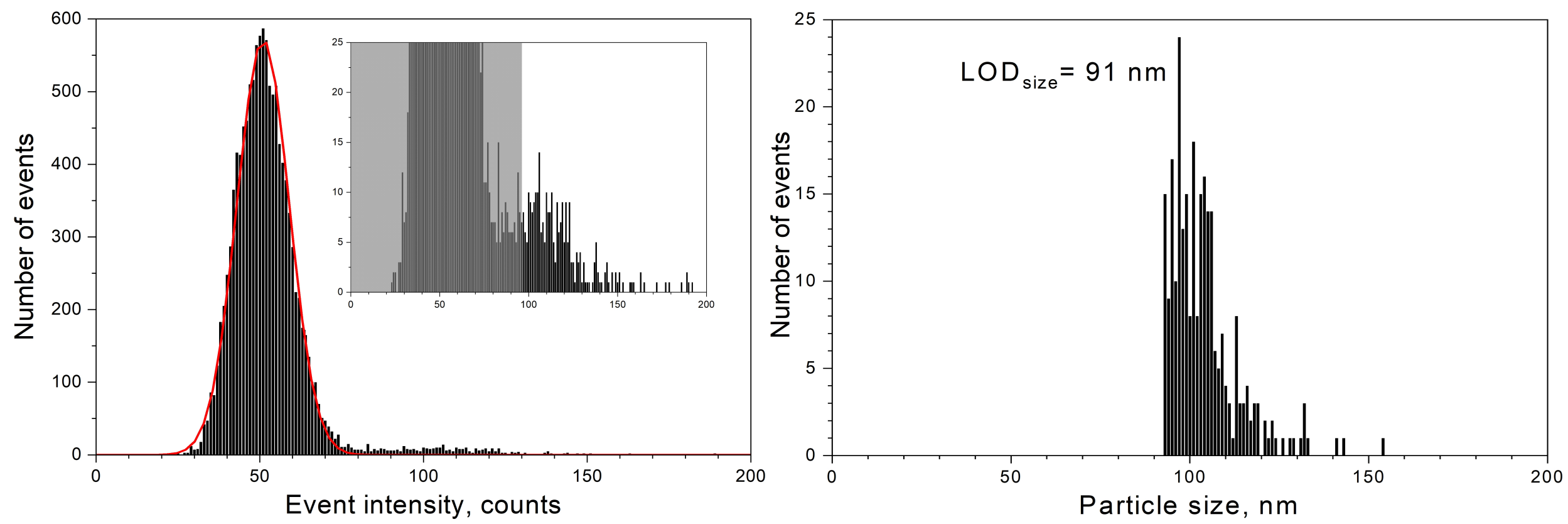

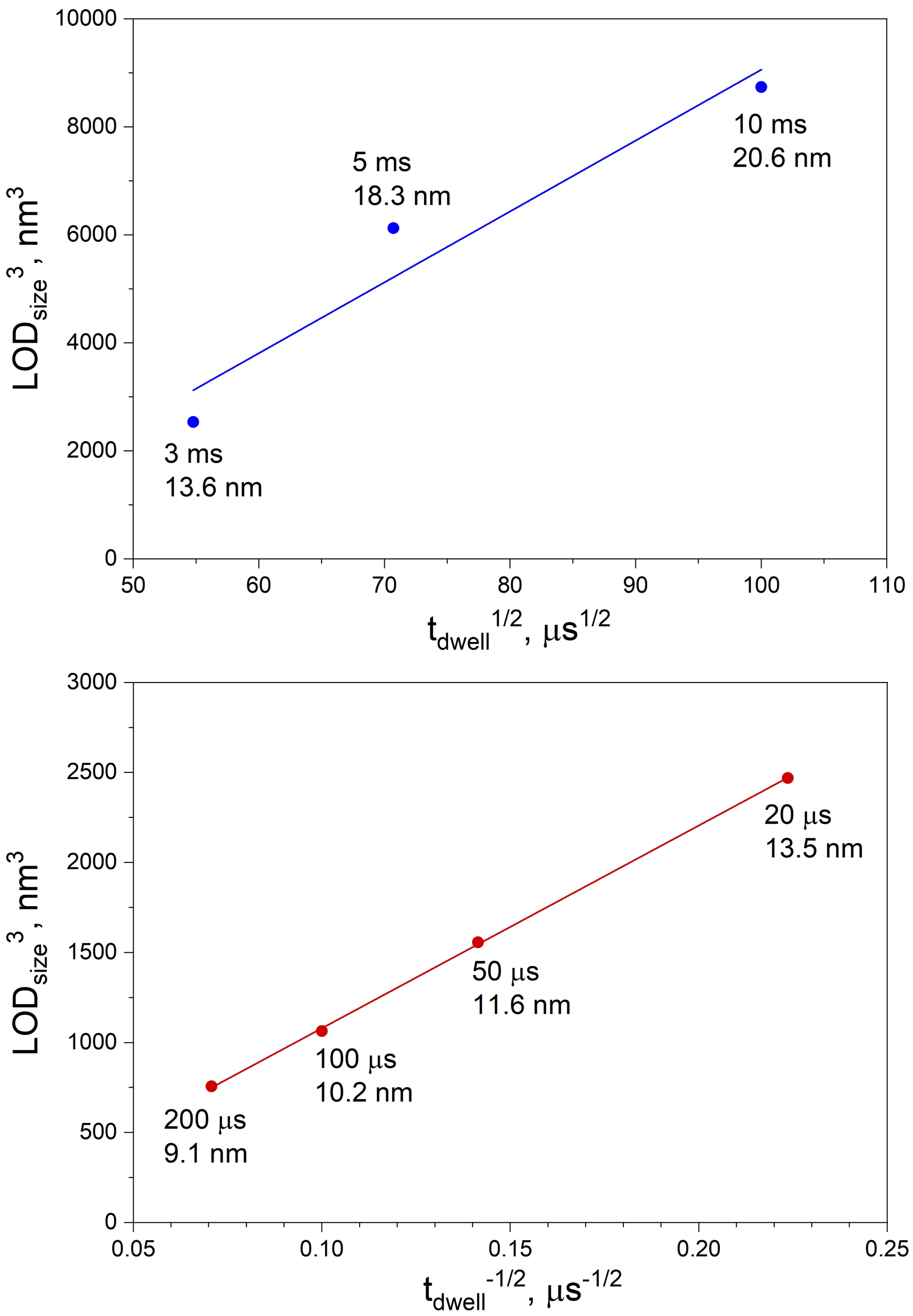
Table 1. Theoretical and experimental dissolved element mass concentration limits of detection $\left(L O D_{d i s}\right)$ for silver $\left({ }^{107} \mathrm{Ag}\right)$ measured in SP-ICP-MS mode at different dwell times. Total acquisition time: $60 \mathrm{~s}$. Number of replicates: 10 .

\begin{tabular}{|c|c|c|c|c|c|c|c|c|}
\hline $\begin{array}{l}\text { dwell } \\
\text { time }\end{array}$ & $\begin{array}{l}\text { number of } \\
\text { readings }\end{array}$ & cps & counts & counts & $R S D_{\bar{B}}$ & $\operatorname{cps}\left(\mu \mathrm{g} \mathrm{L}^{-1}\right)^{-1}$ & $\begin{array}{c}\mathrm{LOD}_{\text {dis }} \\
\text { theoretical } \\
\mathrm{ng} \mathrm{L}^{-1}\end{array}$ & $\begin{array}{c}\operatorname{LOD}_{\text {dis }} \\
\text { experimental } \\
\mathrm{ng} \mathrm{L}^{-1}\end{array}$ \\
\hline \multicolumn{9}{|l|}{$\mu \mathrm{s}$} \\
\hline 100 & 600000 & $36 \pm 1$ & $2160 \pm 60$ & $1.07 \times 10^{-4}$ & 2.97 & $8.95 \times 10^{4}$ & 0.026 & 0.036 \\
\hline 50 & 1200000 & $38 \pm 1$ & $2280 \pm 60$ & $3.87 \times 10^{-5}$ & 2.04 & $9.01 \times 10^{4}$ & 0.026 & 0.026 \\
\hline 20 & 3000000 & $38 \pm 1$ & $2280 \pm 60$ & $2.12 \times 10^{-5}$ & 2.79 & $9.03 \times 10^{4}$ & 0.026 & 0.035 \\
\hline
\end{tabular}


Table 2. Expressions for the critical values and limits of detection in SP-ICP-MS.

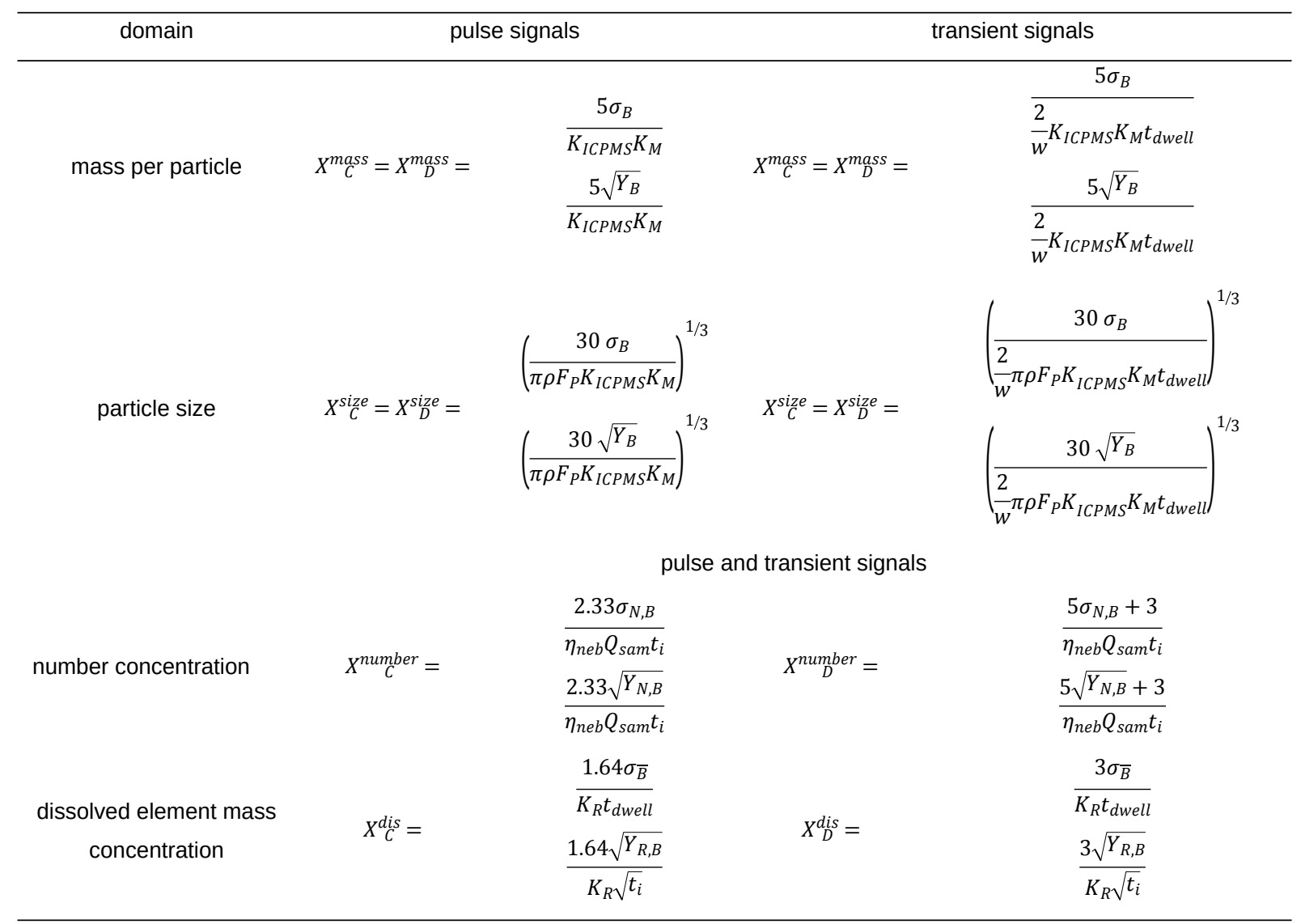


Table 3. Particle size and dissolved element mass concentration LODs.

\begin{tabular}{|c|c|c|c|c|c|c|c|}
\hline \multirow[t]{2}{*}{ element } & \multirow[t]{2}{*}{ isotope } & \multirow[t]{2}{*}{ particle composition } & \multirow[t]{2}{*}{$\begin{array}{c}\mathrm{K}_{\mathrm{R}}^{(\mathrm{a})} \\
\operatorname{cps}\left(\mu \mathrm{g} \mathrm{L}^{-1}\right)^{-1}\end{array}$} & \multirow[t]{2}{*}{$\begin{array}{c}\mathrm{Y}_{\mathrm{R}, \mathrm{B}}(\mathrm{a}) \\
\mathrm{cps}\end{array}$} & \multicolumn{2}{|c|}{$\begin{array}{c}\text { LOD }_{\text {size }} \text { e(b) }^{(n m} \\
\end{array}$} & $\begin{array}{c}\mathrm{LOD}_{\text {dis }}{ }^{(\mathrm{d})} \\
\mathrm{ng} \mathrm{L}^{-1}\end{array}$ \\
\hline & & & & & $\mathrm{t}_{\mathrm{dwell}}=5 \mathrm{~ms}$ & $\mathrm{t}_{\mathrm{dwell}}=100 \mu \mathrm{s}^{(\mathrm{c})}$ & \\
\hline $\mathrm{Ag}$ & 107 & $\mathrm{Ag}$ & 62644 & 203 & 17.4 & 12.3 & 0.09 \\
\hline Al & 27 & $\mathrm{Al}$ & 140231 & 1771 & 29.9 & 21.2 & 0.1 \\
\hline & & $\mathrm{Al}_{2} \mathrm{O}_{3}$ & & & 32.6 & 23.0 & \\
\hline As & 75 & As & 10876 & 24 & 26.7 & 18.9 & 0.2 \\
\hline & & $\mathrm{As}_{2} \mathrm{O}_{3}$ & & & 33.7 & 23.9 & \\
\hline $\mathrm{Au}$ & 197 & $\mathrm{Au}$ & 27343 & 21 & 12.7 & 9.0 & 0.06 \\
\hline B & 11 & B & 26333 & 4745 & 60.3 & 42.7 & 1.0 \\
\hline & & $\mathrm{B}_{2} \mathrm{O}_{3}$ & & & 93.8 & 66.3 & \\
\hline $\mathrm{Ba}$ & 137 & $\mathrm{Ba}$ & 22924 & 34 & 26.0 & 18.4 & 0.1 \\
\hline & & $\mathrm{BaSO}_{4}$ & & & 28.6 & 20.2 & \\
\hline $\mathrm{Be}$ & 9 & $\mathrm{Be}$ & 15758 & 1 & 18.6 & 13.1 & 0.02 \\
\hline $\mathrm{Bi}$ & 209 & $\mathrm{Bi}$ & 131040 & 15 & 9.0 & 6.3 & 0.01 \\
\hline & & $\mathrm{Bi}_{2} \mathrm{O}_{3}$ & & & 9.6 & 6.8 & \\
\hline $\mathrm{Ca}$ & 44 & $\mathrm{Ca}$ & 147864 & 11780 & 48.5 & 34.3 & 0.3 \\
\hline & & $\mathrm{CaO}$ & & & 42.0 & 29.7 & \\
\hline & & $\mathrm{CaCO}_{3}$ & & & 54.6 & 38.6 & \\
\hline $\mathrm{Cd}$ & 111 & $\mathrm{Cd}$ & 14972 & 2 & 14.1 & 10.0 & 0.04 \\
\hline & & CdSe & & & 19.3 & 13.6 & \\
\hline $\mathrm{Ce}$ & 140 & $\mathrm{Ce}$ & 108913 & 7 & 9.6 & 6.8 & 0.01 \\
\hline & & $\mathrm{CeO}_{2}$ & & & 9.8 & 7.0 & \\
\hline Co & 59 & Co & 103622 & 270 & 16.2 & 11.5 & 0.06 \\
\hline & & $\mathrm{CoO}$ & & & 19.6 & 13.9 & \\
\hline & & $\mathrm{Co}_{3} \mathrm{O}_{4}$ & & & 20.4 & 14.4 & \\
\hline $\mathrm{Cr}$ & 52 & $\mathrm{Cr}$ & 89534 & 84751 & 47.8 & 33.8 & 1.3 \\
\hline & & $\mathrm{Cr}_{2} \mathrm{O}_{3}$ & & & 60.3 & 42.6 & \\
\hline $\mathrm{Cu}$ & 65 & $\mathrm{Cu}$ & 26502 & 58 & 19.7 & 14.0 & 0.1 \\
\hline & & $\mathrm{CuO}$ & & & 24.2 & 17.1 & \\
\hline Dy & 163 & Dy & 37892 & 0.1 & 6.1 & 4.3 & 0.003 \\
\hline & & $\mathrm{Dy}_{2} \mathrm{O}_{3}$ & & & 6.6 & 4.7 & \\
\hline $\mathrm{Er}$ & 166 & $\mathrm{Er}$ & 51046 & 0.1 & 5.5 & 3.9 & 0.002 \\
\hline & & $\mathrm{Er}_{2} \mathrm{O}_{3}$ & & & 5.8 & 4.1 & \\
\hline $\mathrm{Eu}$ & 153 & $\mathrm{Eu}$ & 74744 & 0.3 & 6.9 & 4.9 & 0.003 \\
\hline & & $\mathrm{Eu}_{2} \mathrm{O}_{3}$ & & & 6.5 & 4.6 & \\
\hline $\mathrm{Gd}$ & 157 & Gd & 30872 & 0.1 & 6.7 & 4.8 & 0.004 \\
\hline & & $\mathrm{Gd}_{2} \mathrm{O}_{3}$ & & & 7.2 & 5.1 & \\
\hline $\mathrm{Hf}$ & 180 & $\mathrm{Hf}$ & 54727 & 2 & 7.6 & 5.4 & 0.009 \\
\hline & & $\mathrm{HfO}_{2}$ & & & 9.0 & 6.3 & \\
\hline $\mathrm{Hg}$ & 5 & $\mathrm{Hg}$ & 2209 & 98 & 43.0 & 30.4 & 1.7 \\
\hline Ho & 165 & Ho & 149531 & 0.1 & 3.8 & 2.7 & 0.001 \\
\hline & & $\mathrm{Ho}_{2} \mathrm{O}_{3}$ & & & 4.1 & 2.9 & \\
\hline In & 115 & In & 171019 & 6 & 7.7 & 5.4 & 0.005 \\
\hline & & $\ln _{2} \mathrm{O}_{3}$ & & & 8.2 & 5.8 & \\
\hline & & $\ln (\mathrm{OH})_{3}$ & & & 10.3 & 7.3 & \\
\hline Ir & 193 & Ir & 79601 & 4 & 6.5 & 4.6 & 0.01 \\
\hline La & 139 & La & 568165 & 2.1 & 4.6 & 3.3 & 0.001 \\
\hline & & $\mathrm{La}_{2} \mathrm{O}_{3}$ & & & 4.8 & 3.4 & \\
\hline $\mathrm{Li}$ & 7 & $\mathrm{Li}$ & 62259 & 85 & 40.6 & 28.7 & 0.06 \\
\hline Lu & 175 & Lu & 152549 & 0.1 & 3.7 & 2.6 & 0.001 \\
\hline & & $\mathrm{Lu}_{2} \mathrm{O}_{3}$ & & & 3.9 & 2.8 & \\
\hline $\mathrm{Mg}$ & 24 & $\mathrm{Mg}$ & 188923 & 4782 & 37.0 & 26.2 & 0.1 \\
\hline & & $\mathrm{MgO}$ & & & 33.6 & 23.8 & \\
\hline $\mathrm{Mn}$ & 55 & $\mathrm{Mn}$ & 146823 & 1181 & 19.6 & 13.9 & 0.09 \\
\hline & & $\mathrm{Mn}_{2} \mathrm{O}_{3}$ & & & 26.2 & 18.5 & \\
\hline Mo & 95 & Mo & 19064 & 3 & 12.7 & 9.0 & 0.03 \\
\hline & & $\mathrm{MoO}_{3}$ & & & 18.8 & 13.3 & \\
\hline $\mathrm{Na}$ & 23 & $\mathrm{Na}$ & 210199 & 47730 & 63.7 & 45.0 & 0.4 \\
\hline $\mathrm{Nd}$ & 143 & $\mathrm{Nd}$ & 15940 & 0.9 & 12.8 & 9.0 & 0.02 \\
\hline & & $\mathrm{Nd}_{2} \mathrm{O}_{3}$ & & & 13.1 & 9.3 & \\
\hline $\mathrm{Ni}$ & 60 & $\mathrm{Ni}$ & 21914 & 36 & 19.5 & 13.8 & 0.1 \\
\hline & & $\mathrm{NiO}$ & & & 23.3 & 16.5 & \\
\hline $\mathrm{Pb}$ & 208 & $\mathrm{~Pb}$ & 80277 & 175 & 15.2 & 10.7 & 0.06 \\
\hline & & $\mathrm{PbO}$ & & & 16.5 & 11.7 & \\
\hline $\mathrm{Pd}$ & 105 & $\mathrm{Pd}$ & 30498 & 5 & 11.4 & 8.1 & 0.03 \\
\hline $\operatorname{Pr}$ & 141 & $\operatorname{Pr}$ & 131954 & 0.9 & 6.3 & 4.5 & 0.003 \\
\hline & & $\mathrm{Pr}_{6} \mathrm{O}_{11}$ & & & 6.8 & 4.8 & \\
\hline $\mathrm{Pt}$ & 195 & $\mathrm{Pt}$ & 24533 & 0 & 5.3 & 3.7 & 0.005 \\
\hline $\mathrm{Rh}$ & 103 & $\mathrm{Rh}$ & 157201 & 2 & 5.7 & 4.0 & 0.004 \\
\hline & & $\mathrm{Rh}_{2} \mathrm{O}_{3}$ & & & 7.0 & 4.9 & \\
\hline $\mathrm{Ru}$ & 101 & $\mathrm{Ru}$ & 26899 & 2 & 9.7 & 6.9 & 0.02 \\
\hline & & $\mathrm{RuO}_{2}$ & & & 12.9 & 9.1 & \\
\hline $\mathrm{Sb}$ & 121 & $\mathrm{Sb}$ & 33214 & 8 & 14.6 & 10.3 & 0.03 \\
\hline & & $\mathrm{Sb}_{2} \mathrm{O}_{3}$ & & & 16.7 & 11.8 & \\
\hline & & $\mathrm{Sb}_{2} \mathrm{O}_{5}$ & & & 19.3 & 13.6 & \\
\hline $\mathrm{Sc}$ & 45 & $\mathrm{Sc}$ & 80869 & 2507 & 36.6 & 25.9 & 0.2 \\
\hline & & $\mathrm{Sc}_{2} \mathrm{O}_{3}$ & & & 38.8 & 27.4 & \\
\hline $\mathrm{Se}$ & 82 & $\mathrm{Se}$ & 1816 & 194 & 72.8 & 51.5 & 3.0 \\
\hline $\mathrm{Si}$ & 29 & $\mathrm{Si}$ & 10969 & 120537 & 148.5 & 105.0 & 12.3 \\
\hline
\end{tabular}




\begin{tabular}{|c|c|c|c|c|c|c|c|}
\hline \multirow{3}{*}{$\mathrm{Sm}$} & & $\mathrm{SiO}_{2}$ & & & 183.3 & 129.6 & \\
\hline & 147 & $\mathrm{Sm}$ & 19342 & 0.9 & 11.6 & 8.2 & 0.02 \\
\hline & & $\mathrm{Sm}_{2} \mathrm{O}_{3}$ & & & 12.2 & 8.6 & \\
\hline \multirow[t]{2}{*}{ Sn } & 118 & Sn & 40690 & 257 & 23.5 & 16.6 & 0.2 \\
\hline & & $\mathrm{SnO}_{2}$ & & & 25.9 & 18.3 & \\
\hline \multirow[t]{2}{*}{$\mathrm{Sr}$} & 88 & $\mathrm{Sr}$ & 174518 & 264 & 20.7 & 14.6 & 0.04 \\
\hline & & $\mathrm{SrCO}_{3}$ & & & 22.1 & 15.6 & \\
\hline \multirow[t]{2}{*}{$\mathrm{Tb}$} & 159 & $\mathrm{~Tb}$ & 153955 & 0.1 & 3.9 & 2.8 & 0.001 \\
\hline & & $\mathrm{Tb}_{4} \mathrm{O}_{7}$ & & & 4.3 & 3.0 & \\
\hline \multirow[t]{2}{*}{$\mathrm{Te}$} & 125 & $\mathrm{Te}$ & 3237 & 1 & 22.0 & 15.6 & 0.1 \\
\hline & & $\mathrm{TeO}_{2}$ & & & 24.5 & 17.3 & \\
\hline \multirow[t]{2}{*}{$\mathrm{Ti}$} & 47 & $\mathrm{Ti}$ & 8757 & 43 & 34.0 & 24.1 & 0.3 \\
\hline & & $\mathrm{TiO}_{2}$ & & & 41.4 & 29.3 & \\
\hline \multirow[t]{2}{*}{$\mathrm{TI}$} & 205 & $\mathrm{TI}$ & 112528 & 12 & 8.6 & 6.1 & 0.01 \\
\hline & & $\mathrm{Tl}_{2} \mathrm{O}_{3}$ & & & 9.4 & 6.6 & \\
\hline \multirow[t]{2}{*}{$\mathrm{Tm}$} & 169 & $\mathrm{Tm}$ & 157368 & 0.3 & 4.5 & 3.2 & 0.001 \\
\hline & & $\mathrm{Tm}_{2} \mathrm{O}_{3}$ & & & 4.8 & 3.4 & \\
\hline \multirow[t]{2}{*}{ v } & 51 & V & 109688 & 441 & 19.6 & 13.9 & 0.07 \\
\hline & & $\mathrm{V}_{2} \mathrm{O}_{3}$ & & & 24.1 & 17.0 & \\
\hline \multirow[t]{2}{*}{ Y } & 89 & $Y$ & 107231 & 5 & 10.4 & 7.3 & 0.008 \\
\hline & & $\mathrm{Y}_{2} \mathrm{O}_{3}$ & & & 10.8 & 7.6 & \\
\hline \multirow[t]{2}{*}{$\mathrm{Yb}$} & 173 & $\mathrm{Yb}$ & 25406 & 0.2 & 8.4 & 6.0 & 0.007 \\
\hline & & $\mathrm{Yb}_{2} \mathrm{O}_{3}$ & & & 8.0 & 5.7 & \\
\hline \multirow[t]{2}{*}{$\mathrm{Zn}$} & 66 & $\mathrm{Zn}$ & 35387 & 1479 & 33.3 & 23.5 & 0.4 \\
\hline & & $\mathrm{ZnO}$ & & & 38.7 & 27.4 & \\
\hline
\end{tabular}

(a) Ultrapure water.

(b) Quadrupole ICP-MS. Analyte transport efficiency: 5\% (cyclonic spray chamber and concentric nebulizer), sample flow rate:

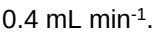

(c) Time-width of particle events: $500 \mu \mathrm{s}$.

(d) Total acquisition time: $60 \mathrm{~s}$. 
Table 4. Number concentration LODs for different commercial sample introduction configurations.

\begin{tabular}{cccc}
\hline sample introduction system & $\begin{array}{c}\eta_{\text {neb }} \\
\%\end{array}$ & $\begin{array}{c}\mathrm{Q}_{\text {sam }} \\
\mathrm{mL} \mathrm{min}^{-1}\end{array}$ & $\begin{array}{c}\mathrm{LOD}_{\text {number }}{ }^{-1} \\
\mathrm{~L}^{-1}\end{array}$ \\
\hline $\begin{array}{c}\text { cyclonic spray chamber }+ \\
\text { concentric nebulizer (Glass Expansion) } \\
\text { baffled cyclonic spray chamber }+ \\
\text { concentric nebulizer (Meinhard) }\end{array}$ & 2.6 & 1.1 & $1.0 \times 10^{5}$ \\
$\begin{array}{c}\text { Asperon spray chamber }+ \\
\text { high efficiency nebulizer (Meinhard) }\end{array}$ & 37.7 & 0.4 & $1.4 \times 10^{5}$ \\
\hline (a) & & & \\
\hline
\end{tabular}

(a) Total acquisition time: $60 \mathrm{~s}$. 


\title{
About detectability and limits of detection in single particle inductively coupled plasma mass spectrometry
}

\author{
Francisco Laborda *, Ana C. Gimenez-Ingalaturre, Eduardo Bolea, Juan R. Castillo \\ Group of Analytical Spectroscopy and Sensors (GEAS) \\ Institute of Environmental Sciences (IUCA) \\ University of Zaragoza \\ Pedro Cerbuna 12, 50009 Zaragoza, Spain.
}

\section{S1. Overview of the concentration LOD concept}

When analysing a number of blank samples (concentration, $X$, equal to zero), a distribution of blank signals around $Y_{B}$ with a given standard deviation $\left(\sigma_{\mathrm{B}}\right)$ is obtained (left distributions in figure $\mathrm{S} 1$ ). Since there can be samples containing no analyte but producing signals higher than $Y_{B}$, a threshold value should be defined in order to decide whether the analyte is present or not in a sample. This threshold is called the critical value $\left(Y_{C}\right)$, and it is defined as the response of the instrument above which an observed signal is reliably attributed to the presence of the analyte. The selection of this critical level implies a certain probability $\alpha$ that the analyte was falsely detected in a blank sample producing a type I error. On the other hand, when analyzing a sample containing analyte that produces a distribution of signals around a value equal of higher than $Y_{C}$, there is a probability $\beta$ of falsely concluding that the analyte is not present. Once $Y_{C}$ has been defined, a minimum detectable value in the signal domain $\left(Y_{D}\right)$ can be established as the signal corresponding to an analyte concentration that gives a specified probability $\beta$ of producing a type II error. Thus, $Y_{D}$ can be defined as the smallest value of the signal at which the probability that it exceeds its critical value is $1-\beta$. The relationships between type I and type II errors, $\alpha$ and $\beta$ probabilities, as well as $Y_{C}$ and $Y_{D}$ are exemplified in Figure S1a. 


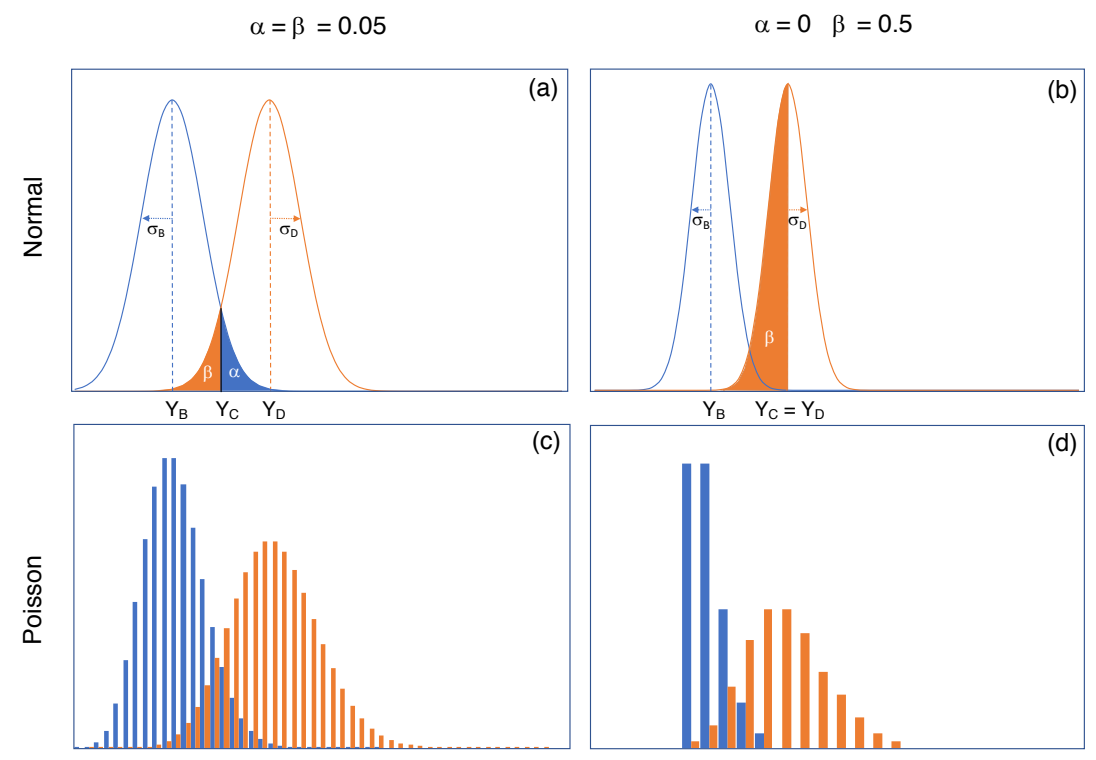

Figure S1. Concentration LOD approach. Type I and Type II errors, $\alpha$ and $\beta$ respectively, and relationship between $Y_{C}$ and $Y_{D}$ with different criteria, signal values applied to continuous normal and discrete Poisson distributions. (a) and (c) $Y_{B}=10$; (b) and (d) $Y_{B}=1$.

If the distributions of the signals are considered normal, with a well-known standard deviation (it is assumed to have been derived from a large number of observations of the blank), the critical value can be presented as:

$$
Y_{C}=Y_{B}+k \sigma_{\mathrm{B}}
$$

where $k$ denotes the (1- $\alpha)$ quantile of the standard normal distribution $\left(z_{1-\alpha}\right)$. If the standard deviations are constant in the range from $Y_{B}$ to $Y_{D}\left(\sigma_{\mathrm{B}}=\sigma_{\mathrm{D}}\right)$, and the probability of producing type I and type II errors is the same $(\alpha=\beta)$, the minimum detectable value is given by:

$$
Y_{D}=Y_{B}+2 k \sigma_{\mathrm{B}}
$$

Equations $\mathrm{S} 1$ and $\mathrm{S} 2$ can be expressed as net signals $\left(S=Y-Y_{B}\right)$ :

$$
\begin{aligned}
& S_{C}=k \sigma_{\mathrm{B}} \\
& S_{D}=2 k \sigma_{\mathrm{B}}
\end{aligned}
$$

When the probability of type I and type II errors is set at $0.05\left(z_{1-\alpha}=z_{1-\beta}=1.645\right)$ :

$$
S_{D}=3.29 \sigma_{\mathrm{B}}
$$

although it is also expressed as:

$$
S_{D}=3 \sigma_{\mathrm{B}}
$$

This expression can be interpreted as a rounding off of equation S5, where type I and type II errors are both considered (in fact, $\alpha=\beta=0.067$ ), but also a limit of detection definition based on considering $Y_{D}=Y_{C}$, which involves that $\alpha=0.00135$ and $\beta=0.5$ (figure S1.b). 
The transformation of $Y_{C}$ and $Y_{D}$ (or $S_{C}$ and $S_{D}$ ) to the concentration domain $\left(X_{C}\right.$ and $X_{D}$, respectively) involves the use of a sensitivity factor $(b)$, which relates the signal $Y$ to the concentration $X$ through a calibration function $(Y=a+b X)$. The minimum detectable value in the concentration domain becomes the limit of detection expressed as:

$$
\mathrm{LOD}=X_{D}=3.29 \frac{\sigma_{\mathrm{B}}}{b}
$$

or

$$
\mathrm{LOD}=X_{D}=3 \frac{\sigma_{\mathrm{B}}}{b}
$$

which is the expression most frequently found in textbooks and literature.

As we have seen, this basic approach is based on the standard deviation of the blank, and involves knowing $Y_{B}$ and $\sigma_{B}$, by performing a number of measurement of a blank under the same conditions (20 according to IUPAC [1], 10 according to EURACHEM [2]), as well as the sensitivity factor. For paired measurements, the standard deviation of the net signal is derived from $\sigma^{2}=\sigma_{D}^{2}+\sigma_{B}^{2}=2 \sigma_{B}^{2}\left(\sigma_{\mathrm{B}}=\sigma_{\mathrm{D}}\right)$, and $k$ increases by a factor of $\sqrt{2}$, same as the expressions for critical values and limits of detection [3].

If counting techniques, like mass spectrometry, are considered, then the analytical systems become heteroscedastic (the standard deviation of the signal depends on its magnitude) and the signals assume only discrete values, following Poisson distributions. Poisson distributions show a significant asymmetry for low signal values, although for sufficiently large values ( $Y>5$ counts [4]), they can be approximated to normal distributions, as it is shown in figures S1c and S1d for $Y_{B}$ equal to 10 and 1, respectively. Since in Poisson distributions the mean is equal to the variance $\left(Y=\sigma^{2}\right)$, the previous approach must be adapted. The critical value can be expressed then as:

$$
Y_{C}=Y_{B}+k \sigma_{\mathrm{B}}=Y_{B}+k \sqrt{Y_{B}}
$$

Because $\sigma_{B} \neq \sigma_{D}, \sigma_{B}^{2}=Y_{B}$ and $\sigma_{D}^{2}=Y_{D}$, equation S2 for $\alpha=\beta$, becomes:

$$
Y_{D}=Y_{B}+k^{2}+2 Y_{C}=Y_{B}+k^{2}+2 k \sqrt{Y_{\mathrm{B}}}
$$

Equations $\mathrm{S} 9$ and $\mathrm{S} 10$ can be expressed with respect to net signals as:

$$
\begin{aligned}
& S_{C}=1.64 \sqrt{Y_{\mathrm{B}}} \\
& S_{D}=2.71+3.29 \sqrt{Y_{\mathrm{B}}}
\end{aligned}
$$

Equation S12 shows that $S_{D}$ will never be equal to zero, even in the case of a blank equal to zero $\left(Y_{B}=\sigma_{\mathrm{B}}=0\right)$. 
Table S1 summarizes common expressions used for estimation of critical and minimum detectable values for $\alpha=\beta=0.05$, with Poisson distributions.

Table S1. Expressions used for estimation of net critical and minimum detectable values for $\alpha=\beta=0.05$ [3]. For gross values $\left(Y_{C}\right.$ and $\left.Y_{D}\right)$ expressions, $Y_{B}$ must be added.

\begin{tabular}{|c|c|c|c|c|}
\hline \multirow[t]{2}{*}{ distribution } & \multicolumn{2}{|c|}{ well known blank } & \multicolumn{2}{|c|}{ paired measurements } \\
\hline & critical value & $\begin{array}{l}\text { minimum detectable } \\
\text { value }\end{array}$ & critical value & $\begin{array}{l}\text { minimum detectable } \\
\text { value }\end{array}$ \\
\hline normal & $S_{C}=1.64 \sigma_{B}$ & $S_{D}=3.29 \sigma_{B}$ & $S_{C}=2.33 \sigma_{B}$ & $S_{D}=4.65 \sigma_{B}$ \\
\hline Poisson & $S_{C}=1.64 \sqrt{Y_{B}}$ & $S_{D}=2.71+3.29 \sqrt{Y_{B}}$ & $S_{C}=2.33 \sqrt{Y_{B}}$ & $S_{D}=2.71+4.65 \sqrt{Y_{B}}$ \\
\hline
\end{tabular}

\section{References}

[1] IUPAC, Nomenclature, symbols, units and their usage in spectrochemical analysis-II. Data interpretation analytical chemistry division, Spectrochim. Acta, Part B. 33 (1978) 242-245.

[2] B. Magnusson, U. Örnemark, eds., The Fitness for Purpose of Analytical Methods: A Laboratory Guide to Method Validation and Related Topics, Eurachem, 2014.

[3] L.A. Currie, Limits for Qualitative Detection and Quantitative Determination: Application to Radiochemistry, Anal. Chem. 40 (1968) 586-593. doi:10.1021/ac60259a007.

[4] L.A. Currie, On the detection of rare, and moderately rare, nuclear events, J. Radioanal. Nucl. Chem. 276 (2008) 285-297. doi:10.1007/s10967-008-0501-5. 


\section{Glossary}

$b$

sensitivity factor

$k \quad(1-\alpha)$ quantile of the standard normal distribution $\left(z_{1-\alpha}\right)$

LOD limit of detection

$S \quad$ net signal $\left(Y-Y_{B}\right)$

$S_{C} \quad$ net critical value

$S_{D} \quad$ net minimum detectable value

X concentration

$Y \quad$ signal

$Y_{B} \quad$ blank signal or mean intensity of a blank baseline

$Y_{C} \quad$ critical value

$Y_{D} \quad$ minimum detectable value

$Z_{(1-\alpha)} \quad(1-\alpha)$ quantile of the standard normal distribution

$z_{(1-\beta)} \quad(1-\beta)$ quantile of the standard normal distribution

$\alpha \quad$ probability of false positive

$\beta \quad$ probability of false negative

$\varepsilon \quad$ threshold security term

$\eta_{n e b} \quad$ analyte transport efficiency

$\rho \quad$ particle density

$\sigma_{\mathrm{B}} \quad$ standard deviation of a blank signal $Y_{B}$

$\sigma_{\bar{B}} \quad$ standard deviation of the mean intensity of blank baselines

$\sigma_{\mathrm{D}} \quad$ standard deviation of the minimum detectable value $Y_{D}$

$\sigma_{N, B} \quad$ standard deviation of the number of particles events in blanks $Y_{N, B}$ 